US Army Corps

of Engineers ${ }_{\circledast}$

Engineer Research and

Development Center

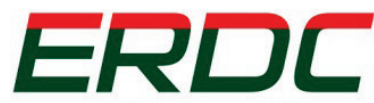

INNOVATIVE SOLUTIONS for a safer, better world

Flood \& Coastal Storm Damage Reduction Program

Seepage and Piping through Levees and Dikes Using 2D and 3D Modeling Codes

Hwai-Ping Cheng, Stephen M. England, June 2016

and Clarissa M. Murray

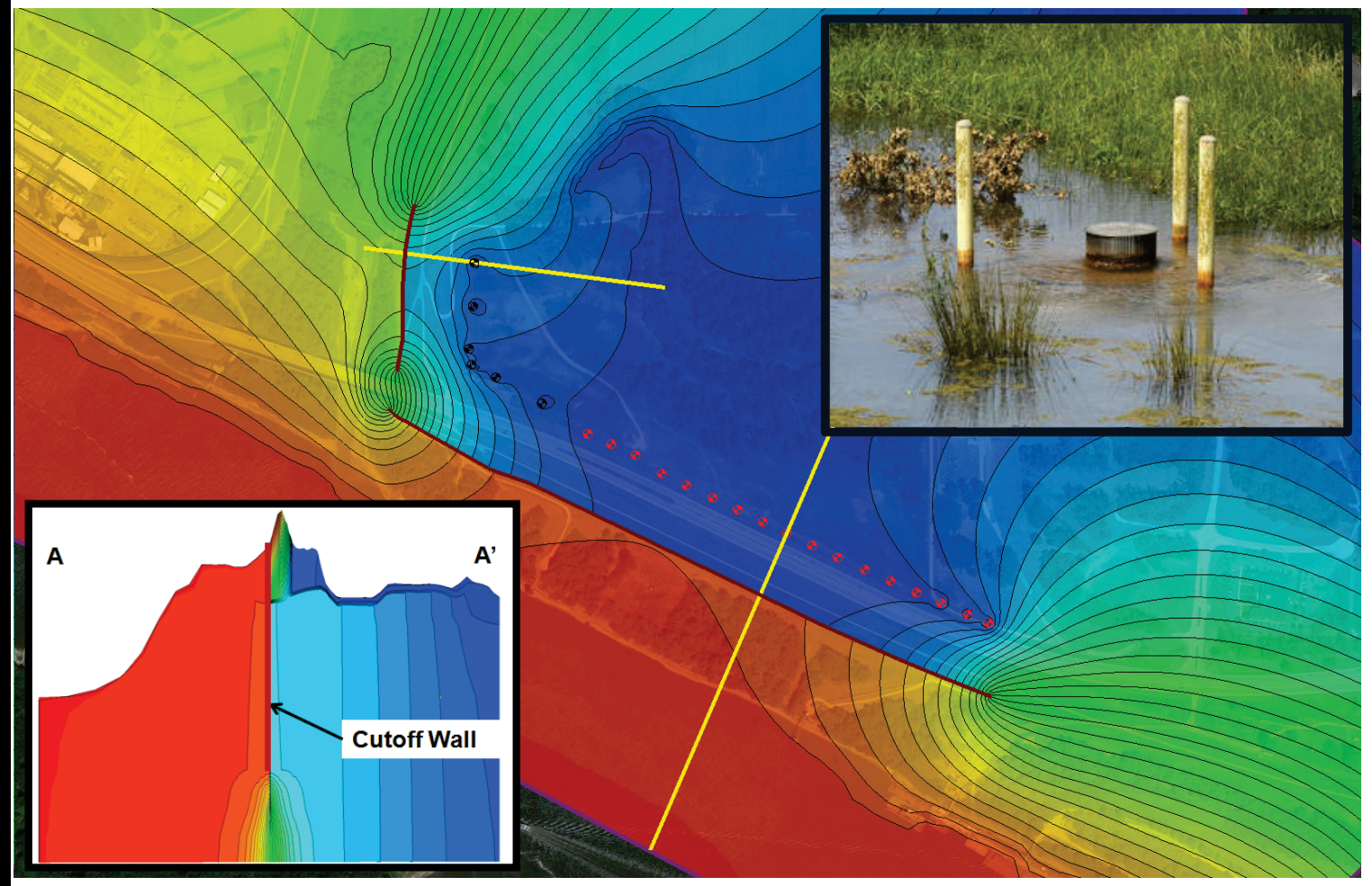


The U.S. Army Engineer Research and Development Center (ERDC) solves the nation's toughest engineering and environmental challenges. ERDC develops innovative solutions in civil and military engineering, geospatial sciences, water resources, and environmental sciences for the Army, the Department of Defense, civilian agencies, and our nation's public good. Find out more at www.erdc.usace.army.mil.

To search for other technical reports published by ERDC, visit the ERDC online library at http://acwc.sdp.sirsi.net/client/default. 


\title{
Seepage and Piping through Levees and Dikes Using 2D and 3D Modeling Codes
}

\author{
Hwai-Ping Cheng \\ Coastal and Hydraulics Laboratory \\ U.S. Army Engineer Research and Development Center \\ 3909 Halls Ferry Road \\ Vicksburg, MS 39180-6199 \\ Stephen M. England and Clarissa M. Murray \\ U.S. Army Corps of Engineers \\ Philadelphia District (NAP) \\ The Wanamaker Building \\ 100 Penn Square East \\ Philadelphia, PA 19107-3390
}

Final report

Approved for public release; distribution is unlimited.

\author{
Prepared for U.S. Army Corps of Engineers \\ $441 \mathrm{G}$ Street NW \\ Washington, DC 20314-1000 \\ Under Project 405372, "3D Analysis of Piping through Levees"
}




\section{Abstract}

The purpose of this Technical Report is to evaluate the benefits of threedimensional (3D) modeling of common seepage and piping issues along embankments over traditional two-dimensional (2D) models. To facilitate the evaluation, one $3 \mathrm{D}$ model, two $2 \mathrm{D}$ cross-sectional models, and one $2 \mathrm{D}$ plan-view model were developed in this study to simulate a simplified real-world situation. This simplified model includes the main channel of a large river, a smaller tributary feeding this river from the north, and levees between the tributary and the river for a flood protection purpose. A set of extreme hydrologic conditions was applied to the models, and results from steady-state simulations were compared. Four scenarios, including Existing Condition, Cutoff Wall Only, Relief Wells Only, and Cutoff Wall and Relief Wells were considered for model comparison. The 2D model results were compared to $3 \mathrm{D}$ model results to determine whether they may be sufficient for specified purposes. The results of this analysis indicate several strengths and weakness of both the $2 \mathrm{D}$ and 3D modeling approaches, as detailed in the Summary section. While a 2D model may be acceptable for a screening-level analysis, a 3D model may be deemed informative for a design-level analysis.

DISCLAIMER: The contents of this report are not to be used for advertising, publication, or promotional purposes. Citation of trade names does not constitute an official endorsement or approval of the use of such commercial products. All product names and trademarks cited are the property of their respective owners. The findings of this report are not to be construed as an official Department of the Army position unless so designated by other authorized documents. 


\section{Contents}

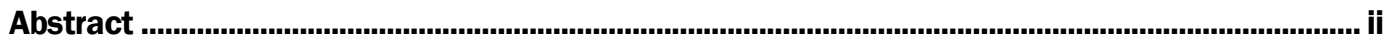

Figures and Tables...................................................................................................................

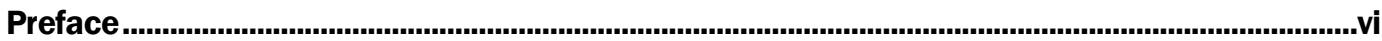

Unit Conversion Factors ......................................................................................................................vii

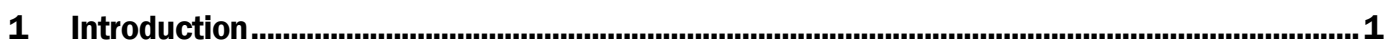

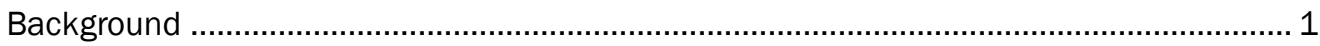

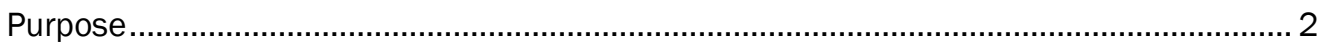

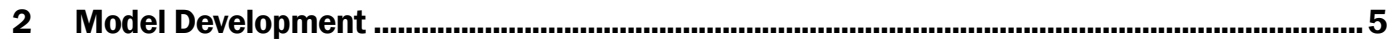

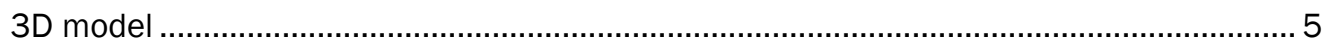

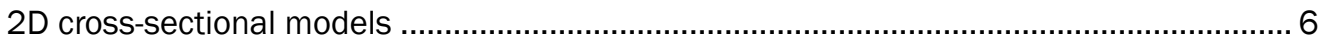

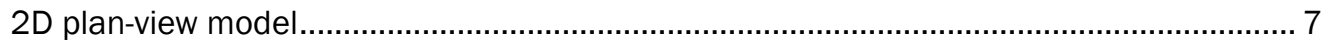

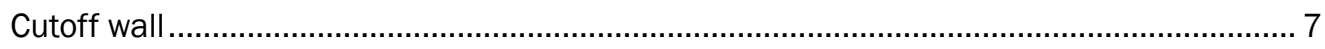

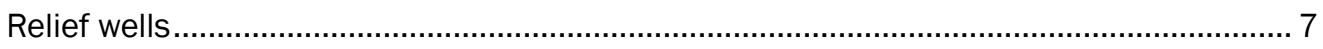

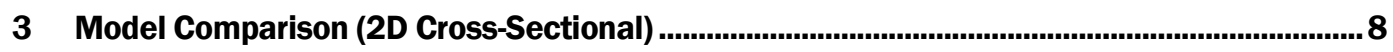

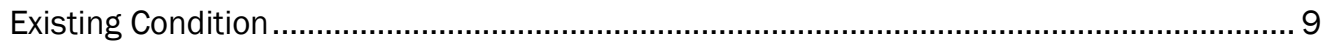

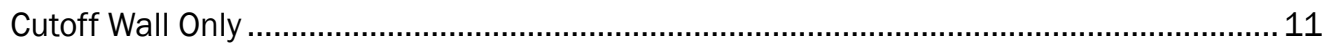

Relief Wells Only .................................................................................................... 13

Cutoff Wall and Relief Wells........................................................................... 15

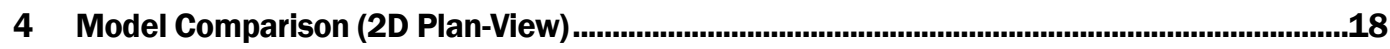

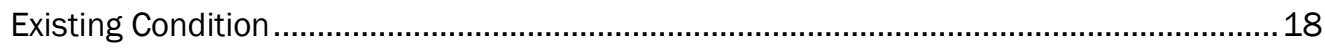

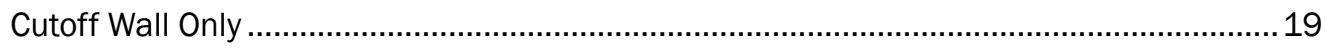

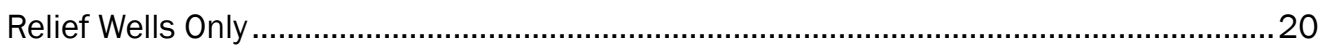

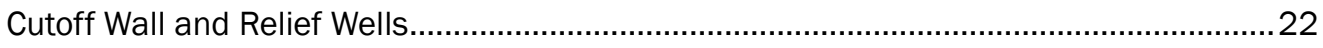

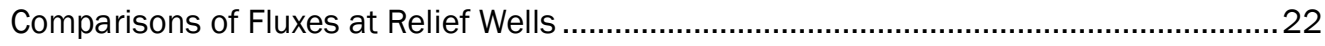

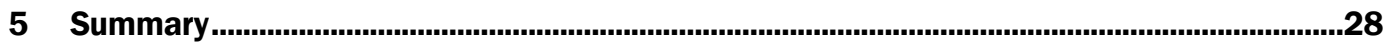

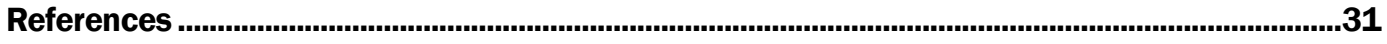

\section{Report Documentation Page}




\section{Figures and Tables}

\section{Figures}

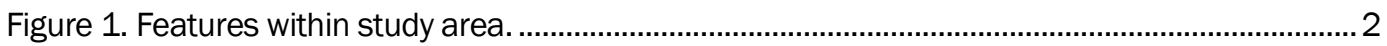

Figure 2. Model domains and simulated improvements................................................................

Figure 3. Study area geology (vertical exaggeration $=10$ )...............................................................

Figure 4. Computed total head distribution in upper sand aquifer from the 3D model

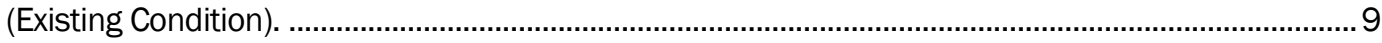

Figure 5. Comparison of total head distribution: 2D cross-sectional vs. 3D at Section A-A'

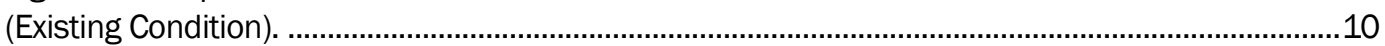

Figure 6. Comparison of total head distribution: 2D cross-sectional vs. 3D at Section B-B' (Existing Condition). ...............................................................................................................................11

Figure 7. Computed total head distribution in upper sand aquifer from the 3D model (Cutoff Wall Only).

Figure 8. Comparison of total head distribution: 2D cross-sectional vs. 3D at Section A-A' (Cutoff Wall Only)

Figure 9. Comparison of total head distribution: 2D Cross-sectional vs. 3D at Section B-B' (Cutoff Wall Only).

Figure 10. Computed total head distribution in upper sand aquifer from the 3D model (Relief Wells Only).

Figure 11. Comparison of total head distribution: 2D cross-sectional vs. 3D at Section A-A' (Relief Wells Only).

Figure 12. Comparison of total head distribution: 2D cross-sectional vs. 3D at Section BB' (Relief Wells Only).

Figure 13. Computed total head distribution in upper sand aquifer from the 3D model (Cutoff Wall and Relief Wells).

Figure 14. Comparison of total head distribution: 2D cross-sectional vs. 3D at Section A-A' (Cutoff Wall and Relief Wells).

Figure 15. Comparison of total head distribution: 2D cross-sectional vs. 3D at Section B-B' (Cutoff Wall and Relief Wells).

Figure 16. Comparison of total head distribution: 2D Plan view vs. 3D comparison at Section A-A' (Existing Condition).

Figure 17. Comparison of total head distribution: 2D Plan view vs. 3D comparison at Section B-B' (Existing Condition).

Figure 18. Comparison of total head distribution: 2D Plan view vs. 3D comparison at Section A-A' (Cutoff Wall Only).

Figure 19. Comparison of total head distribution: 2D Plan view vs. 3D comparison at Section B-B' (Cutoff Wall Only).

Figure 20. Comparison of total head distribution: 2D Plan view vs. 3D comparison at Section A-A' (Relief Wells Only).

Figure 21. Comparison of total head distribution: 2D Plan view vs. 3D comparison at Section B-B' (Relief Wells Only). 
Figure 22. Comparison of total head distribution: 2D Plan view vs. 3D comparison at Section A-A' (Cutoff Wall and Relief Wells) .....................................................................................23

Figure 23. Comparison of total head distribution: 2D Plan view vs. 3D comparison at

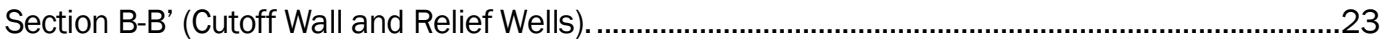

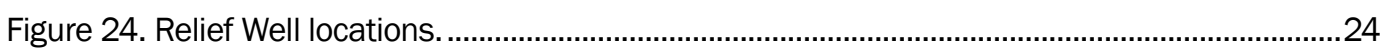

Figure 25. Comparison Relief Well fluxes without cutoff wall: 2D SEEP/W model vs. 3D WASH123D model.

Figure 26. Comparison of Relief Well fluxes with cutoff wall: 2D SEEP/W model vs. 3D WASH123D model.

Figure 27. Comparison of Relief Well fluxes: 2D SEEP/W model vs. simplified 3D WASH123D model.

\section{Tables}

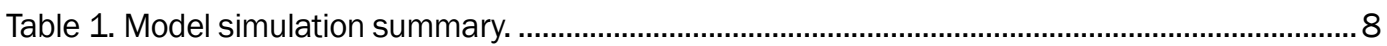

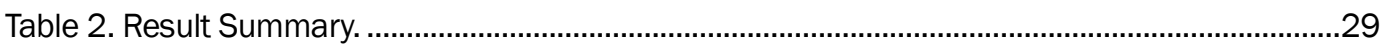




\section{Preface}

This study was conducted for the HQUSACE under Flood and Coastal Storm Damage Reduction Program; Project 405372, "3D Analysis of Piping through Levees.” The technical monitor was Dr. Cary A. Talbot (CEERD-HT).

The work was performed by the Hydrologic Systems Branch of the Flood and Storm Protection Division (CEERD-HF), U.S. Army Engineer Research and Development Center, Coastal and Hydraulics Laboratory (ERDC-CHL). At the time of publication, Dr. Hwai-Ping Cheng was Chief, CEERD-HFH; Dr. Ty V. Wamsley was Chief, CEERD-HF; and William R. Curtis, CEERD-HT, was the Technical Director for the Flood and Coastal Storm Damage Reduction Program. The Director of ERDC-CHL was José E. Sánchez.

Dr. Mark Wahl (CHL) and Neil Schwanz (MVP) reviewed this report and provided valued comments.

The Commander of ERDC was COL Bryan S. Green, and the Director was Dr. Jeffery P. Holland. 


\section{Unit Conversion Factors}

\begin{tabular}{|l|c|l|}
\hline Multiply & By & To Obtain \\
\hline feet & 0.3048 & meters \\
\hline miles (U.S. statute) & $1,609.347$ & meters \\
\hline
\end{tabular}




\section{Introduction}

\section{Background}

Any failure of dams or levees can pose a significant risk to public health and safety (USACE 2010). Recent infrastructure assessments identify an urgent need to assess the reliability of dams and levees as well as to repair and rehabilitate them to ensure adequate performance and public safety. Relief wells and cutoff walls are the two remediation alternatives most commonly used to prevent levee failures.

Relief wells are installed adjacent to earthen embankments to relieve the pore-water pressure downstream of a lake or river and thus to prevent the collapse of the embankment. Impounded water, typically greater during a flood, results in a pressure gradient that causes more water to infiltrate into the embankment and foundation. Water then flows through the soil towards the downstream (land) side of the embankment, potentially resulting in sand boils, liquefaction of the soil, and ultimately destruction of the embankment and foundation. Relief wells act like valves to relieve the water pressure and allow excess water to be diverted safely, for example, to a canal. Relief wells effectively reduce sand boil formation by relieving the water pressure within the embankment.

Cutoff walls are also used to slow or prevent seepage on the land side of an embankment. These cutoff walls are generally constructed along or adjacent to existing embankments. They are constructed using low permeability materials and generally extend from the ground surface to an underlying confining unit (e.g., an aquitard). These cutoff walls reduce the migration of groundwater by either obstructing the flow path within the foundation of the embankment or lengthening the flow path to an extent that the hydraulic head on the downstream side of the cutoff wall is dissipated.

To divert excess water efficiently and effectively, it is necessary to know how fast water would exit through relief wells or pass around and beneath a cutoff wall under various hydrologic conditions. Both two-dimensional (2D) and three-dimensional (3D) modeling tools are available to assess groundwater flow patterns and evaluate the factor of safety (FoS) associated with seepage failures (Cheng et al. 2014). Due to complex geology, topology, land use, embankment characteristics, man-made features, etc., using a 3D model to estimate groundwater flow beneath the embankment can often be more appropriate compared to a 2D model. 


\section{Purpose}

Numerical models are frequently used to evaluate flow patterns in a groundwater system, predict the effects of seepage reduction measures, and ultimately develop a better understanding of the groundwater flow system. Both 2D and 3D models are useful tools for evaluating groundwater flow. However, there are strengths and limitations to each. For this study, the 2012 GeoStudio 2D groundwater model, SEEP/W (Geo-Slope 2012), and the $3 \mathrm{D}$ groundwater module of WASH123D (Yeh et al. 2006) were compared. Each numerical model employs unstructured finite element meshes for their computational domains. The purpose of this study is to evaluate how the $2 \mathrm{D}$ and the $3 \mathrm{D}$ models perform upon modeling seepage across embankments and how the simulated groundwater flow system responds to improvements such as cutoff walls and relief wells.

\section{Approach}

To evaluate the applicability of both the $2 \mathrm{D}$ and $3 \mathrm{D}$ models, a simplified real-world situation was simulated assuming steady-state seepage conditions. As shown in Figure 1, the modeled location is along the main channel of a large river, and a smaller tributary feeds this river from the north. Levees have been constructed along the tributary and the main river to protect low-lying area near the confluence from flooding.

Figure 1. Features within study area.

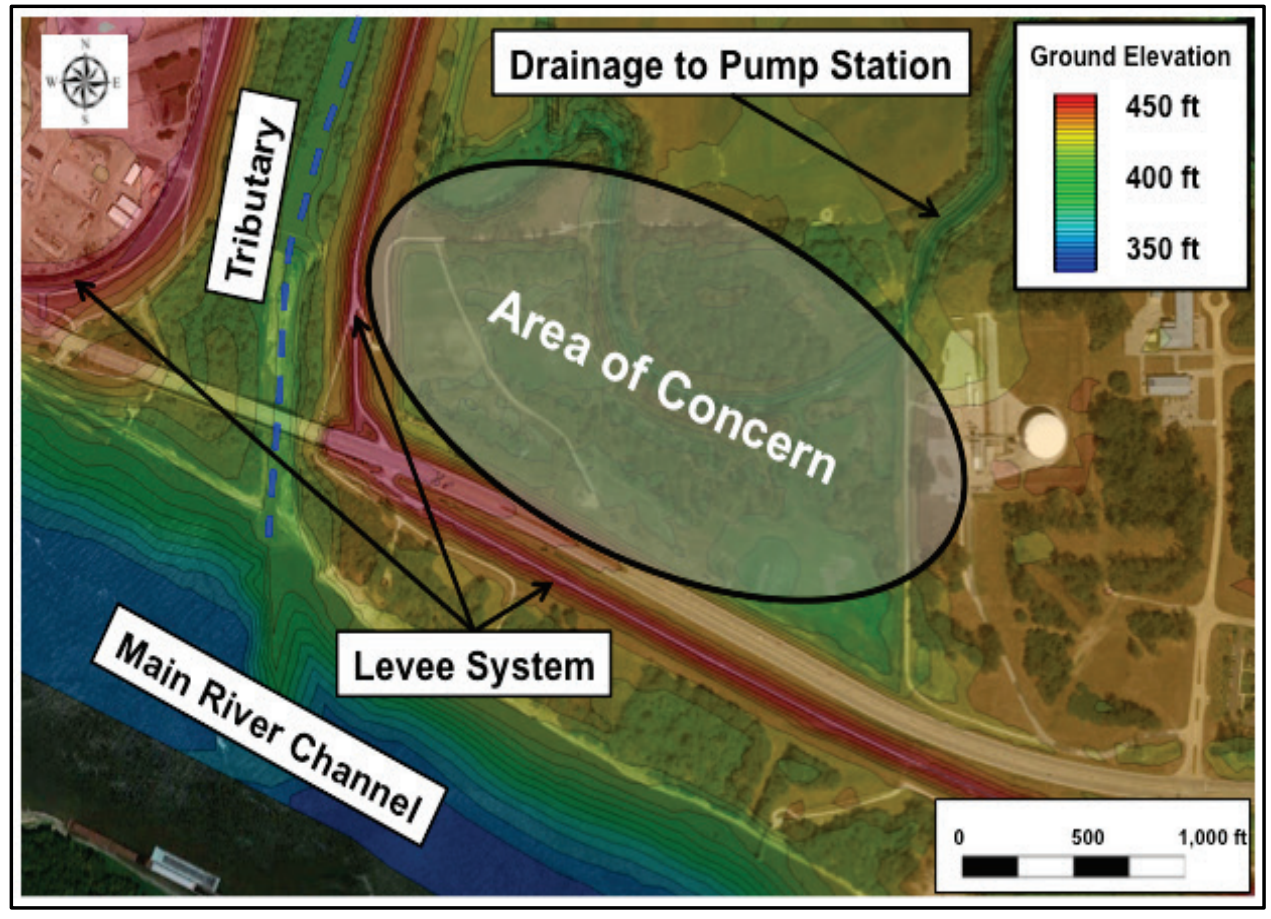


The geology associated with cross-sections AA' and BB' (Figure 2) is relatively uniform with a thin, low permeability clay layer at or near the surface that is underlain by a thicker sequence of higher permeability sands (Figure 3). Below these sands are zones of clay and bedrock (low permeability) that form a natural no-flow boundary at the base of the model domain. Along the main channel of the river (left, Figure 2), the bathymetry is deep enough to penetrate the surficial clay layer. This creates a condition where the water in the main channel is in direct contact with the underlying sand layers. However, the clayey streambed material in the tributary bed may result in a damped connection between the tributary water and the underlying sand layers because the depth of the tributary is substantially shallower than the main river channel (right, Figure 2).

Figure 2. Model domains and simulated improvements.

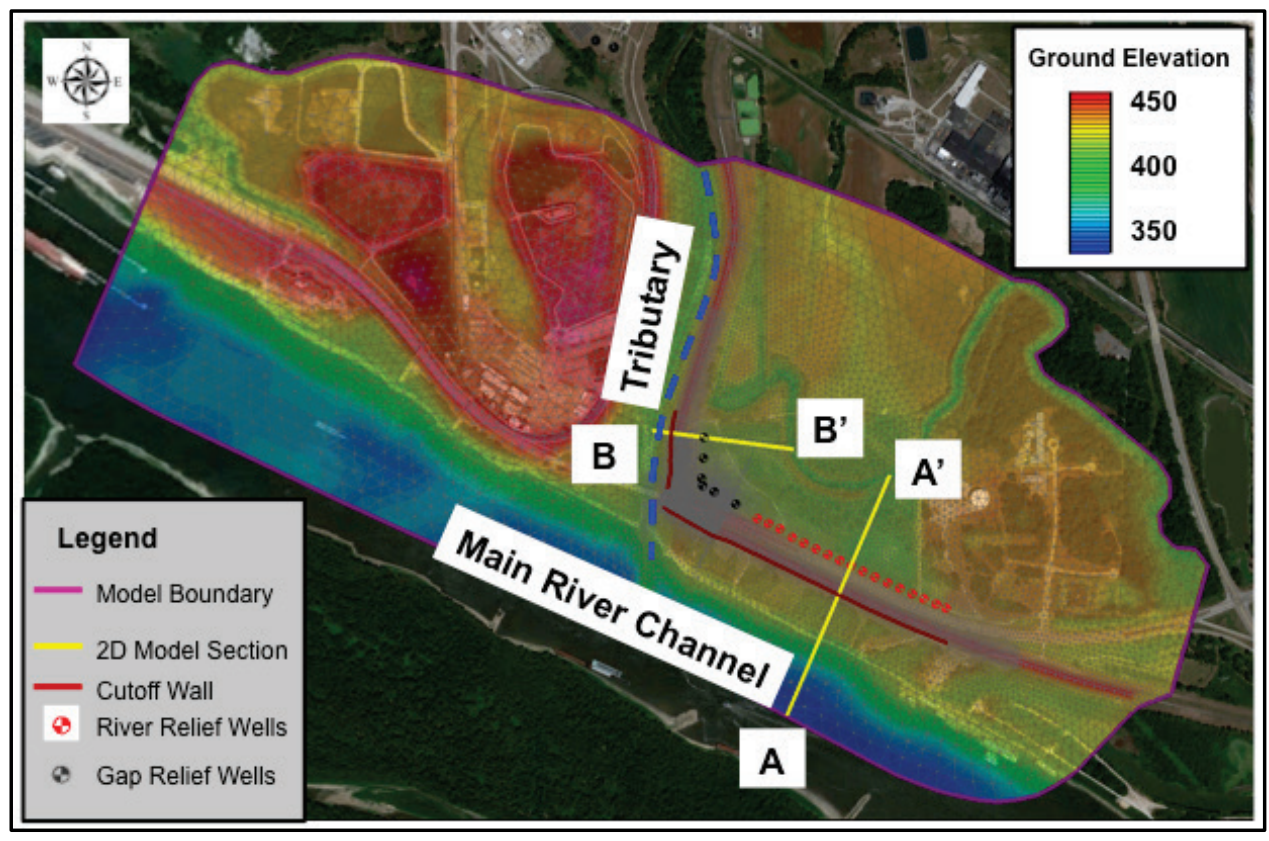

Figure 3. Study area geology (vertical exaggeration $=10$ ).
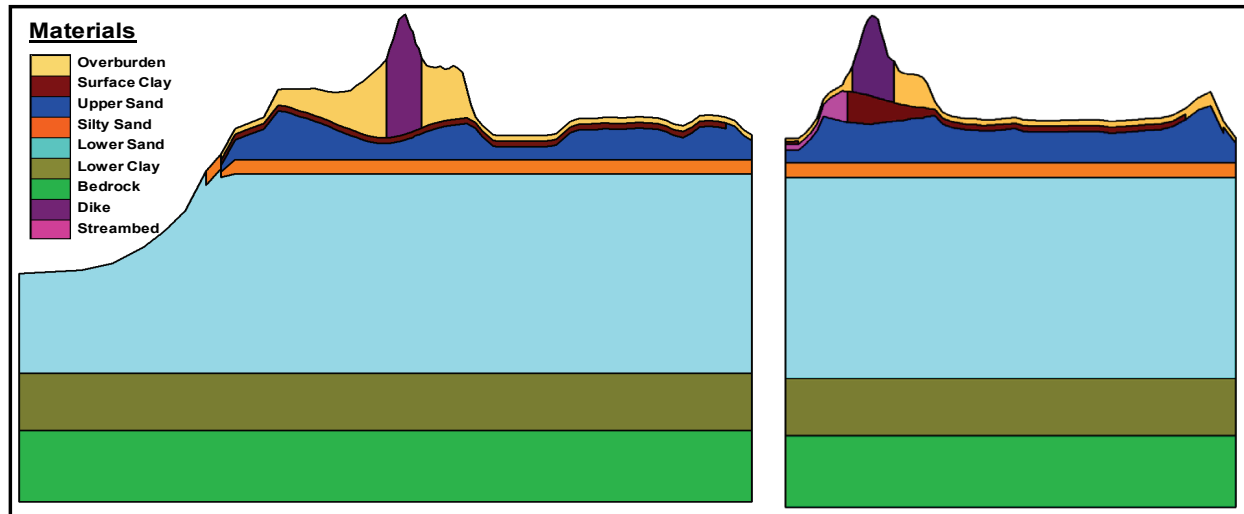

(a) Main River Channel Section (A-A')

(b) Tributary Section (B-B') 
Section 2 of this report describes the development of 3D and 2D computer models used to simulate the simplified situation mentioned above. The $3 \mathrm{D}$ and the 2D cross-sectional models are compared in Section 3 while the $3 \mathrm{D}$ and the 2D plan-view models are compared in Section 4. 


\section{Model Development}

For this study, one 3D model, two 2D cross-sectional models, and one 2D plan-view model were developed. The location of the $3 \mathrm{D}$ model domain and the locations selected for the 2D cross-sectional models are shown in Figure 2. The horizontal resolution used in the $3 \mathrm{D}$ model was greatest in the area of interest to compute the groundwater flow fields adequately under the Existing Condition and with various improvements such as relief wells and a cutoff wall. The $3 \mathrm{D}$ mesh elements were aligned with respect to the cross-sections selected for the 2D modeling (Figure 2). By constructing the $3 \mathrm{D}$ mesh in this manner, each computational node in the 2D cross-sectional models was coincident with a computational node in the $3 \mathrm{D}$ mesh, which as a result eliminated the need to interpolate between computational nodes when comparing the model results. A sensitivity analysis was conducted to determine the mesh resolution used for the $2 \mathrm{D}$ and the $3 \mathrm{D}$ models developed in this study.

\section{D model}

The area of interest was centrally located in the $3 \mathrm{D}$ model domain to minimize potential boundary effects. The model domain is approximately 2 miles along the axis of the main river channel and 0.75 mile along the axis of the tributary. The primary area of interest is the low-lying area northeast of the confluence between the main river channel and the tributary (Figure 1). The 3D mesh was comprised of 222,045 nodes and 411,964 triangular prism elements for computation. Each material layer depicted in Figure 3 was subdivided into two vertical layers of computational elements, resulting in 14 layers of mesh elements over 7 material layers vertically. An extreme flood condition, where both the river and the tributary stages were assumed to be at an elevation of $445 \mathrm{ft}$, was applied for steady-state simulations. Nodes along the surface of the model adjacent to the river and the tributary with elevations less than $445 \mathrm{ft}$ were given a constant head boundary condition of $445 \mathrm{ft}$. Because the bathymetry of the main river channel cuts into the sand aquifers underlying the surface clay, a hydrostatic condition was assumed along the vertical model faces adjacent to the main river. Consequently these vertical model nodes were assigned a constant total head of $445 \mathrm{ft}$. 
During flooding events, the water level within the area of concern (Figure 1) was maintained at an elevation of $412 \mathrm{ft}$ by a pump station fed via the drainage feature to the north of the area of concern, as indicated in Figure 1. The surface model nodes with elevations below $412 \mathrm{ft}$ were thus assigned a constant total head of $412 \mathrm{ft}$.

\section{D cross-sectional models}

Two cross-sectional models, located on cross sections AA' and BB' (Figure 2), were developed. The mesh resolution, geologic layering, and hydrogeologic parameters were consistent with those used in the 3D model. To be consistent with traditional 2D modeling practices, these cross sections were selected so that they were generally along the flow path. Section A-A' was selected to cut across the existing levee along the main river channel. Its southern boundary was coincident with the $3 \mathrm{D}$ model boundary along the main river channel while its northern model boundary was selected such that a constant stage can be maintained due to drainage to the pump station. Section B-B' was selected to cut across the levee adjacent to the tributary. Its eastern model boundary was also selected such that a constant head was kept using surface pumping, and its western boundary was selected along the centerline of the tributary.

Because the 2D and the $3 \mathrm{D}$ models do not have the same boundaries and several assumptions are inherent in the 2D approach, the 2D models were run using a few different options for boundary conditions to bracket a range of possible scenarios. For each 2D model, the upstream (i.e., riverside) and the downstream (i.e., landside) vertical model faces were assumed to be one of the following:

1. Hydrostatic - A direct connection between the surface water stage and the underlying aquifers was assumed, where the head loss through the impervious material in between was neglected.

2. No Flow - The model boundaries were assumed to be along a groundwater divide.

3. From WASH - The results of the 3D model simulation were employed to set up the boundary conditions for the 2D model to provide the greatest consistency between simulation results. Note that this information would not be known if only 2D models were developed. 


\section{D plan-view model}

A plan-view model was built of the same site using SEEP/W. The model simulated heads in the confined upper sand unit (i.e., the geologic layer with blue color in Figure 3). The computational nodes were set at the same $(\mathrm{x}, \mathrm{y})$ locations as the WASH123D model for easy comparison. Hydraulic conductivity for the sand matched that used in the $3 \mathrm{D}$ model. Because of the nature of the 2D plan-view model, this model applies uniform thickness throughout the model domain and assumes no vertical flow into or out of the sand unit.

Boundary conditions were set to be as close to the $3 \mathrm{D}$ model as possible. Specified heads set on the edges of the 3D model (northwest corner and northeast corner) were applied at the same level to the edges of the 2D plan-view model in the same way. Specified heads that were applied to the surface of the WASH123D model were more difficult to replicate in the 2D model because head impacts are dampened as water flows through the units overlying the upper sand. However, head data for the tributary and the small stream east of the tributary (though not shown in Figure 1) that would serve as internal constant head boundary conditions to all areas where the overlying (confining) clay layer exists were missing.

Recharge was applied to the surface of the $3 \mathrm{D}$ model, but it was not applied to the 2D model where it was assumed that a negligible amount of vertical flow would enter the sand unit because of the overlying clay unit.

\section{Cutoff wall}

The cutoff wall was simulated by changing the material type of the associated computational elements along the cutoff wall so that the hydraulic conductivity was set to a small value (e.g., $0.1 \mathrm{ft} /$ day) to mimic the generally impermeable cutoff wall. Note that the cutoff wall is fully penetrating in the 2D plan-view model while the $3 \mathrm{D}$ model has the cutoff wall extended to the top of the rock, which would allow minimal groundwater flow under the cutoff wall through the rock.

\section{Relief wells}

The relief wells were input as specified head points at each relief well location. In the $3 \mathrm{D}$ model, the screen of each relief well extending from the upper sand unit down to the lower sand unit was modeled. Note that this option allows the $3 \mathrm{D}$ model to pull water from neighboring units while the 2D model removes all water from the sand unit only. 


\section{Model Comparison (2D Cross-Sectional)}

Multiple simulations were made using each model to evaluate if the differences observed were resulting from model construction and boundary condition assignment or from the $2 \mathrm{D}$ vs. $3 \mathrm{D}$ configurations. Table 1 summarizes the model simulations that were performed. This ensemble of simulations provided a good insight into the advantages and limitations of both 2D and 3D modeling. The plots shown in Figures 4, 7, 10, and 13 depict the computed heads in the upper sand aquifer below the surficial confining clay from the $3 \mathrm{D}$ models. The cross-sectional graphics given on the lower left of Figures 5, 6, 8, 9, 11, 12, 14, and 15 show the simulation results for the $3 \mathrm{D}$ models, and those given on the lower right of these figures show the simulation results for the 2D models when the WASH123D model results are assumed as boundary conditions (i.e., the "From WASH" simulations shown in Table 1). The plots on top of these figures compare the computed total heads from the $3 \mathrm{D}$ model (i.e., WASH_Base) and the 2D model with the three sets of boundary conditions mentioned previously.

Table 1. Model simulation summary.

\begin{tabular}{|c|c|}
\hline $\begin{array}{l}\text { WASH123D } \\
\text { Simulation }\end{array}$ & SEEP/W Simulation \\
\hline \multirow{3}{*}{$\begin{array}{l}\text { Existing } \\
\text { Condition }\end{array}$} & Hydrostatic (Hydrostatic @ USB ${ }^{1}$ and DSB²) \\
\hline & No Flow (Hydrostatic @ USB; No-Flow @ DSB) \\
\hline & From WASH (Using 3-D Model Results @ USB and DSB) \\
\hline \multirow{3}{*}{ Cutoff Wall Only } & Hydrostatic (Hydrostatic @ USB and DSB) \\
\hline & No Flow (Hydrostatic @ USB; No-Flow @ DSB) \\
\hline & From WASH (Using 3-D Model Results @ USB and DSB) \\
\hline \multirow{3}{*}{$\begin{array}{l}\text { Relief Wells } \\
\text { Only }\end{array}$} & Hydrostatic (Hydrostatic @ USB and DSB) \\
\hline & No Flow (Hydrostatic @ USB; No-Flow @ DSB) \\
\hline & From WASH (Using 3-D Model Results @ USB and DSB) \\
\hline \multirow{3}{*}{$\begin{array}{l}\text { Cutoff Wall and } \\
\text { Relief Wells }\end{array}$} & Hydrostatic (Hydrostatic @ USB and DSB) \\
\hline & No Flow (Hydrostatic @ USB; No-Flow @ DSB) \\
\hline & From WASH (Using 3-D Model Results @ USB and DSB) \\
\hline
\end{tabular}




\section{Existing Condition}

The Existing Condition model simulations assumed flood stage ( $445 \mathrm{ft}$ ) in the river and tributary and an interior drainage level of $412 \mathrm{ft}$, where no improvements were assumed. In this case, groundwater flow was directly from the river sources to the interior drainage sinks.

Figure 4 provides a plan-view representation of the computed groundwater heads in the upper sand aquifer. The flood stage applied to the main channel of the river resulted in a primary groundwater flow pattern from south to north. The vertical leakage across the tributary bed also influenced the computed heads below the tributary. Although the influence of the water in the tributary was damped, a distinct mounding below the tributary was seen and resulted in a west to east flow in this area.

Figure 4. Computed total head distribution in upper sand aquifer from the 3D model (Existing Condition).

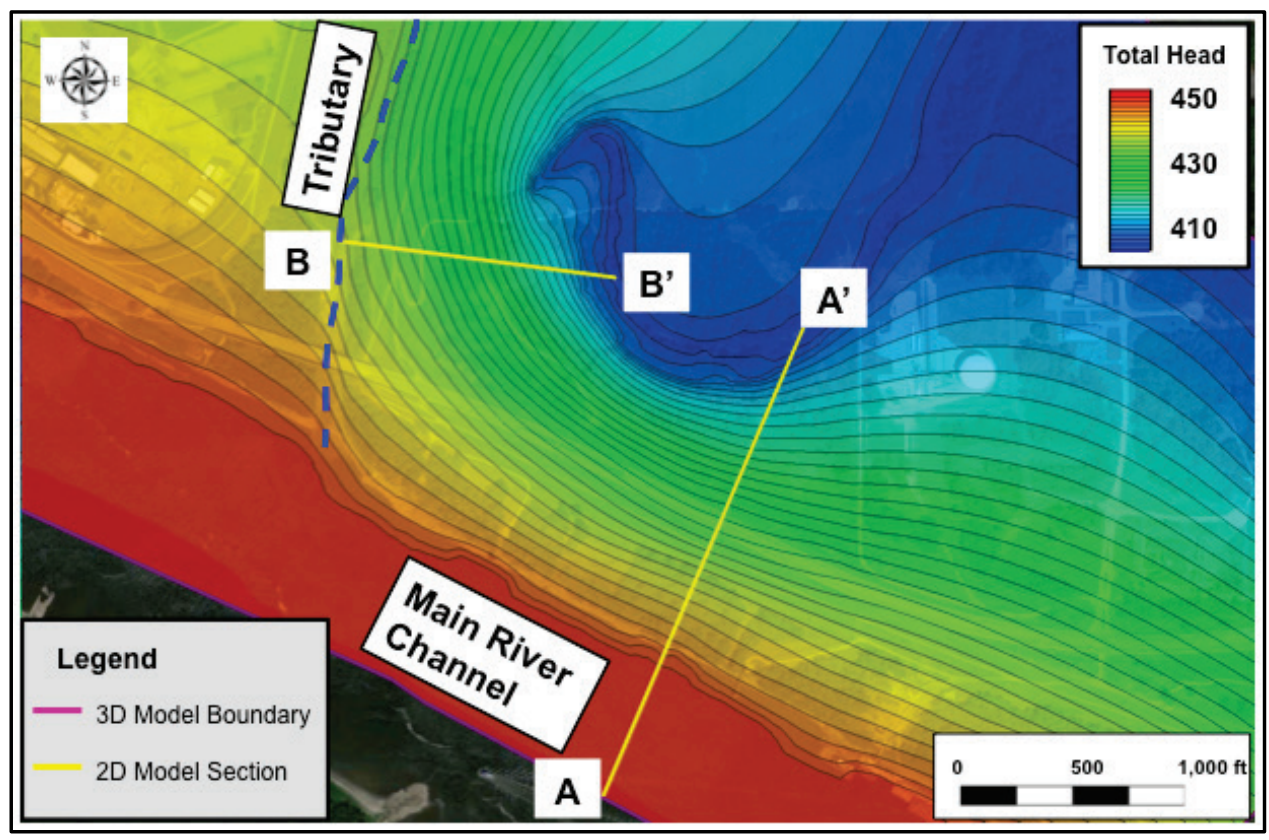

Figure 5 compares the simulated groundwater heads in the $2 \mathrm{D}$ and $3 \mathrm{D}$ models at Section A-A', where the $2 \mathrm{D}$ heads were from the simulation using the "From WASH" boundary condition mentioned above. This depiction is also reasonably representative of the simulations using the "Hydrostatic" and the "No Flow" boundary conditions, as can be seen in the plot of the upper sand unit (top, Figure 5). 
Figure 5. Comparison of total head distribution: 2D cross-sectional vs. 3D at Section A-A' (Existing Condition).

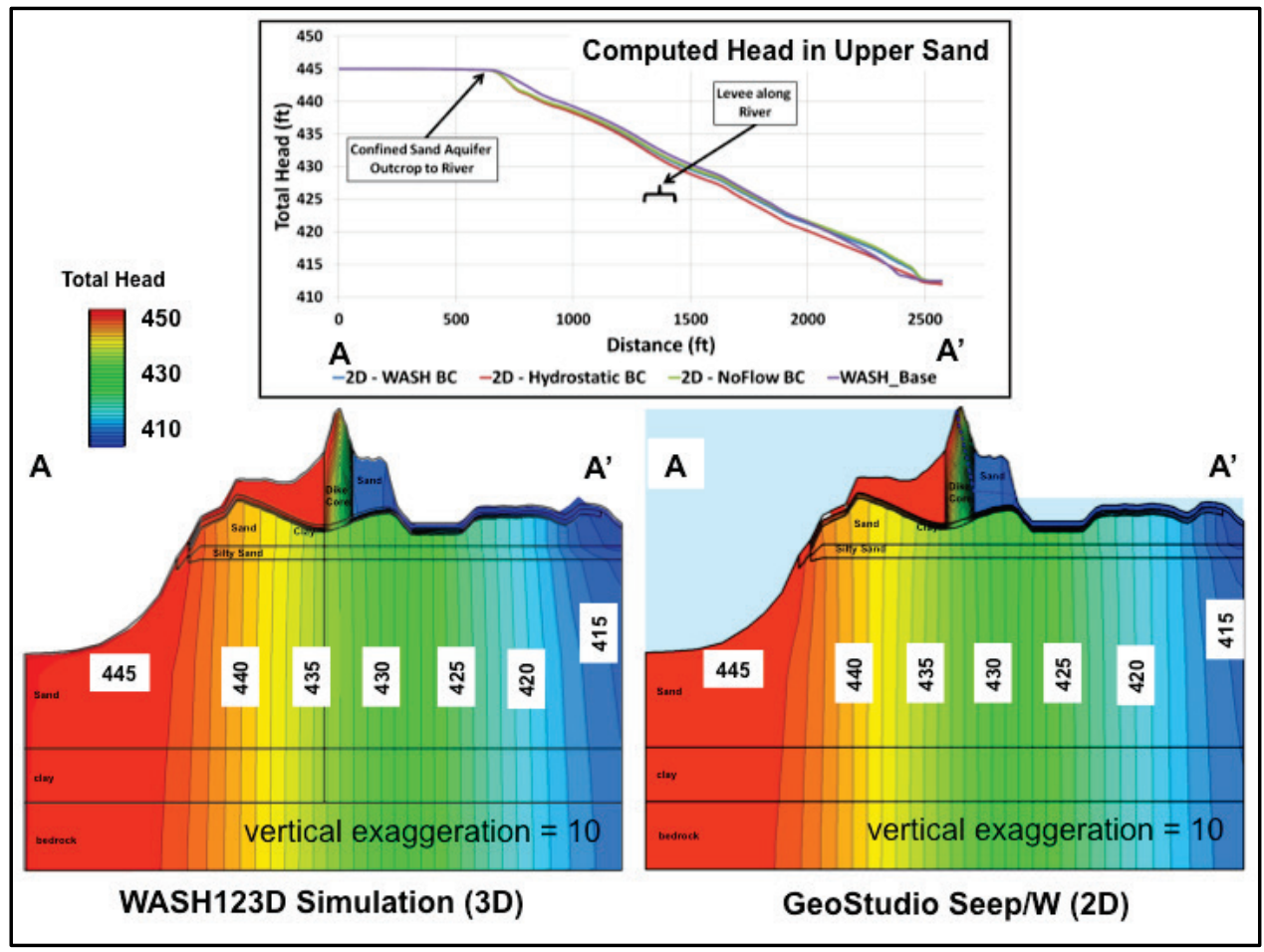

Figure 6 compares the simulated groundwater heads in the $2 \mathrm{D}$ and $3 \mathrm{D}$ models at Section B-B' in the scenario of Existing Condition. The 2D and 3D models compare quite well on the east (right) side of Section B-B', and the computed heads in the 2D model are relatively independent of the boundary condition selected (top, Figure 6). However, significant differences (up to $20 \mathrm{ft}$ ) in the computed heads in the 2D model are observed on the west (left) side of the section (top, Figure 6). These variations in the $2 \mathrm{D}$ model are the result of the boundary condition selected at this location. The computed heads in the 3D model under the simulated tributary are lower (approximately $436 \mathrm{ft}$ ) in comparison to the flood stage ( $445 \mathrm{ft}$ ) directly above this boundary, which is due to the dampening effect of the tributary bed material. The selection of the "Hydrostatic" and the "No Flow" boundary conditions for the 2D model brackets the heads computed in the 3D model but significantly over- or underpredicts the heads at the boundary and across Section B-B' (top, Figure 6). 
Figure 6. Comparison of total head distribution: 2D cross-sectional vs. 3D at Section B-B' (Existing Condition).

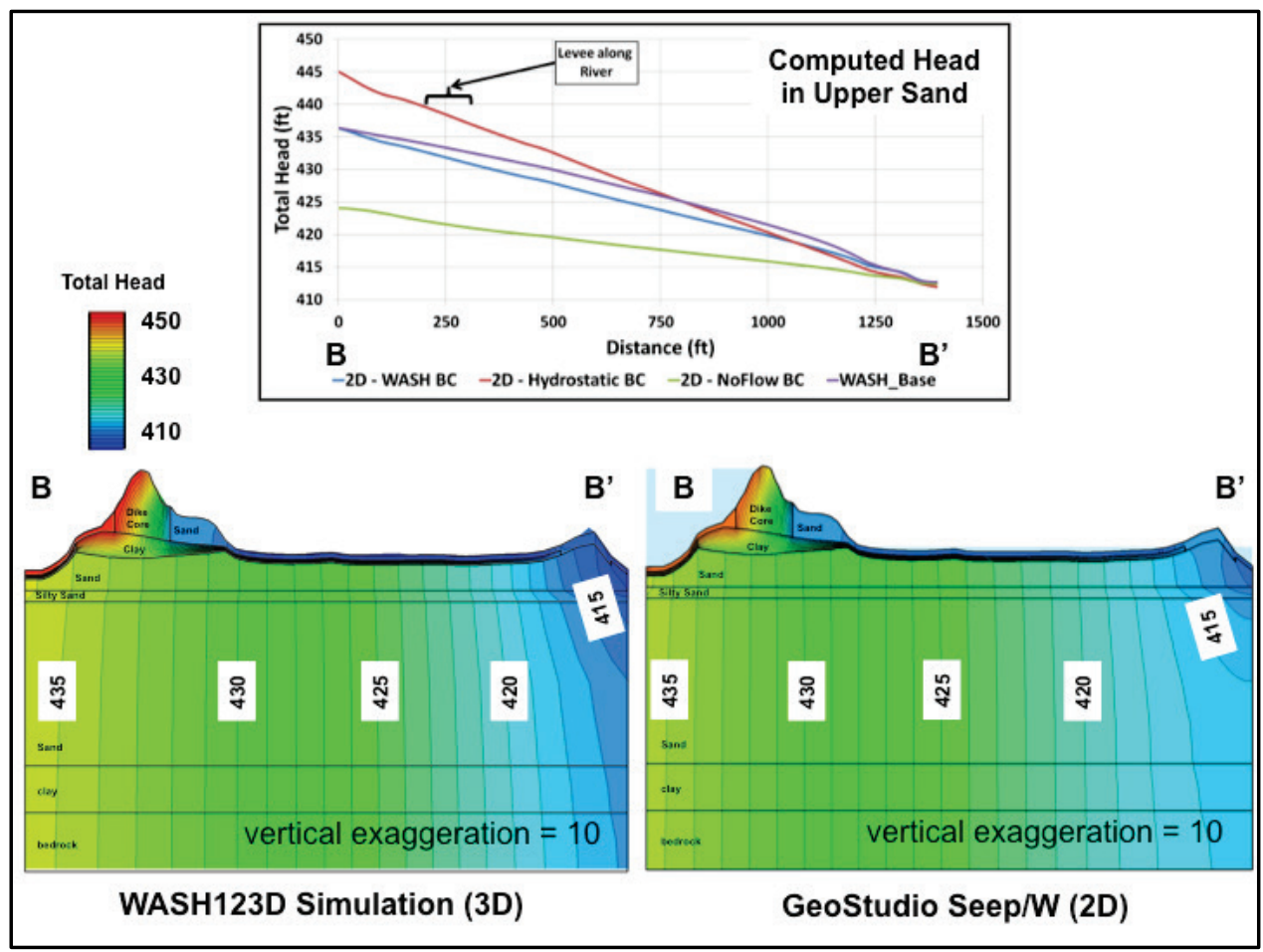

\section{Cutoff Wall Only}

The Cutoff Wall Only model simulations retained the same boundary conditions and hydraulic property assumptions used in the Existing Condition simulations, except that a cutoff wall was added to reduce groundwater heads and the associated seepage issues in the area of concern. Figure 7 provides a plan-view representation of the computed groundwater heads in the upper sand aquifer directly below the surface clay, where end effects around this cutoff wall and through the gap are evident. As shown in Figure 7, the cutoff wall was located along both the main river channel and the tributary. Due to constructability constraints with the existing roadway, a small gap in the cutoff wall was located near the confluence of the river and tributary.

Figure 8 compares the simulated groundwater heads in the $2 \mathrm{D}$ and $3 \mathrm{D}$ models at Section A-A' with the addition of the cutoff wall. Evident in the plot of the upper sand unit (top, Figure 8), the computed heads in the 2D model are reasonably consistent regardless of the boundary conditions applied. A significant difference can be seen immediately down gradient of the cutoff wall, where the $3 \mathrm{D}$ computed total heads were up to $5 \mathrm{ft}$ greater than that computed in the 2D model. Although Section A-A' was more 
than $1,000 \mathrm{ft}$ from the end of the cutoff wall, the $3 \mathrm{D}$ end affects observed in Figure 8 still had a significant influence on the computed heads in the area of concern. The $5 \mathrm{ft}$ higher head computed from the 3D model would result in significantly greater uplift pressures and reduced factors of safety in comparison to the results obtained from the $2 \mathrm{D}$ model.

Figure 7. Computed total head distribution in upper sand aquifer from the 3D model (Cutoff Wall Only).

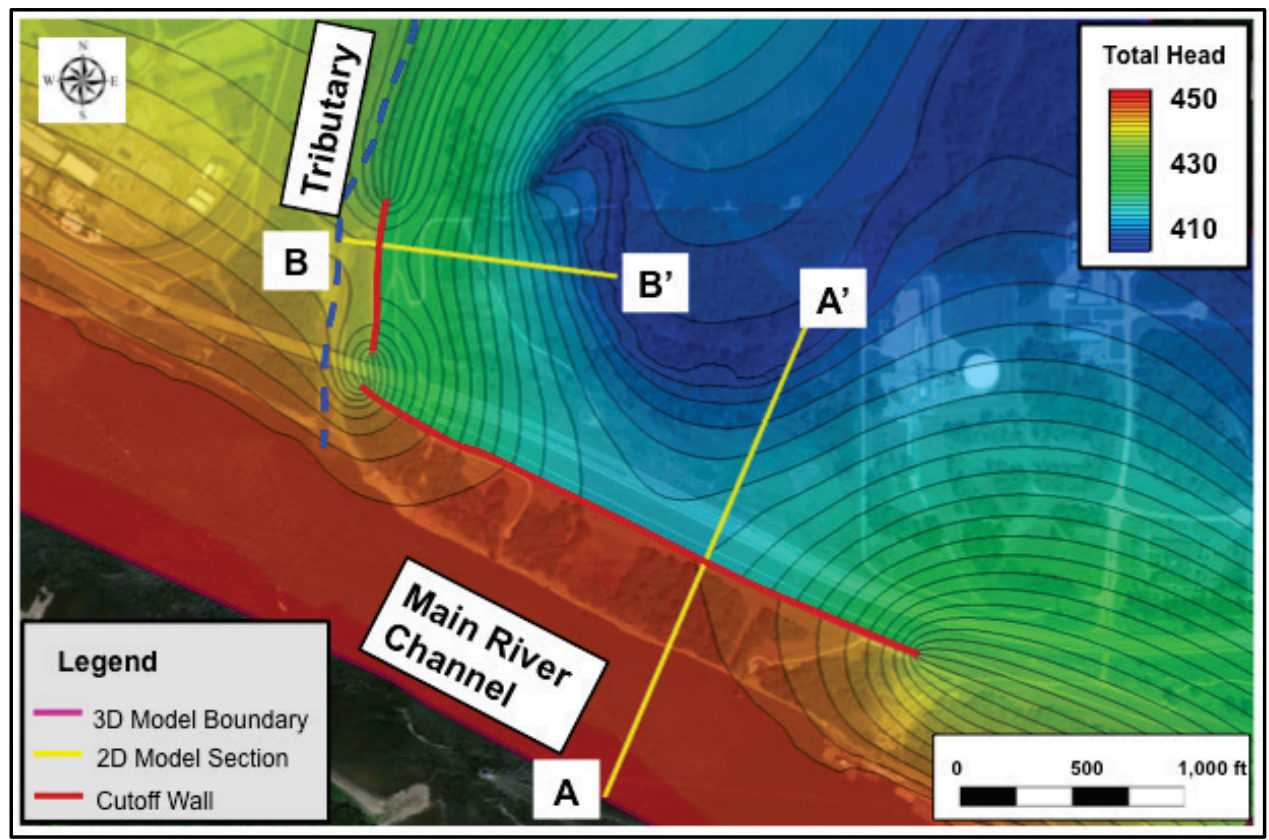

Figure 8. Comparison of total head distribution: 2D cross-sectional vs. 3D at Section A-A' (Cutoff Wall Only).

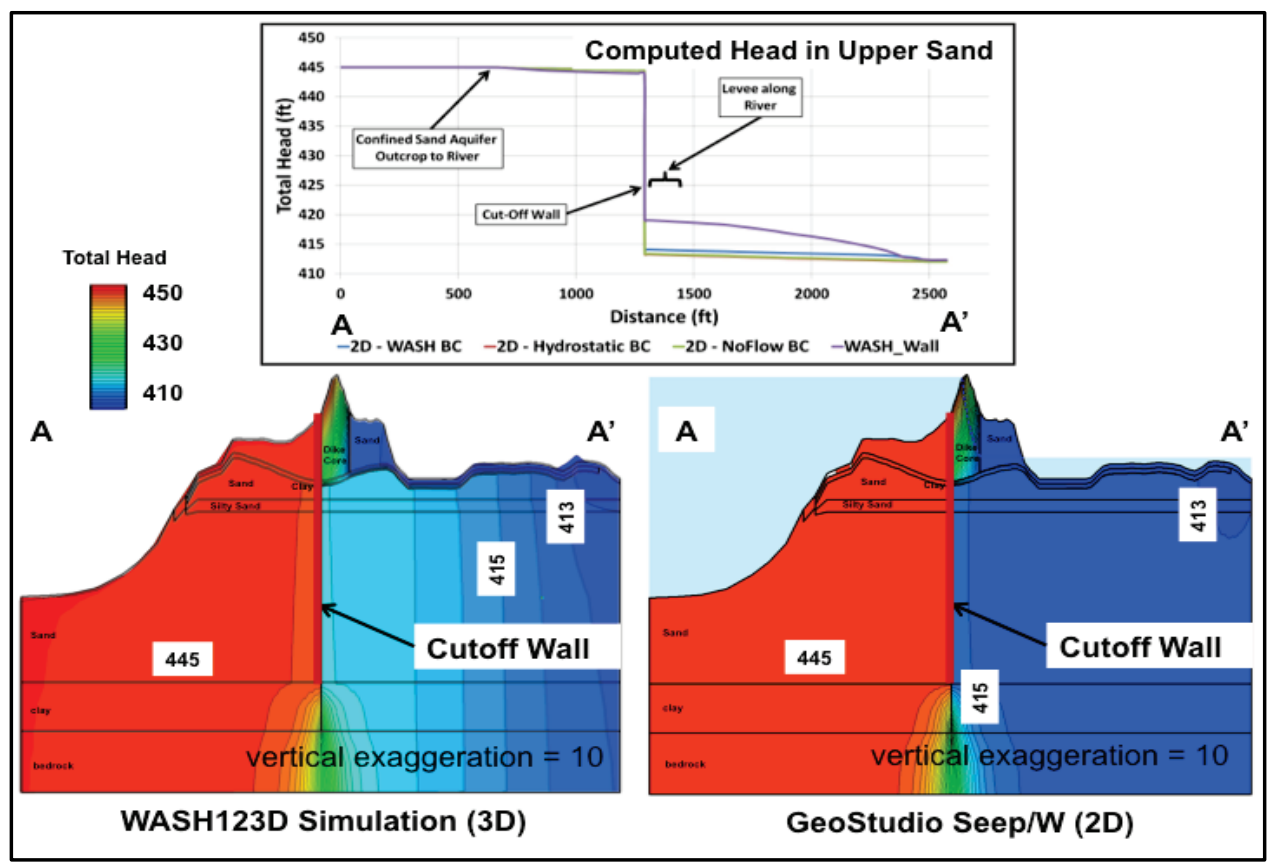


Figure 9 compares the simulated groundwater heads in the $2 \mathrm{D}$ and $3 \mathrm{D}$ models at Section B-B' with the cutoff wall. As shown at top of Figure 9, the 2D model results were relatively insensitive to boundary condition selection for Section B-B' on the east (right) boundary but were sensitive on the west (left) boundary. Due to the effects of flow through the tributary bed material and end effects around the cutoff wall, the simulated heads in the 3D model were lower on the tributary side of the cutoff wall and significantly higher (in excess of $10 \mathrm{ft}$ ) on the land side of the cutoff wall. As noted previously for Section A-A', this would result in significantly greater uplift pressures and reduced $\mathrm{FoS}$ in the $3 \mathrm{D}$ model when compared to the $2 \mathrm{D}$ model.

Figure 9. Comparison of total head distribution: 2D Cross-sectional vs. 3D at Section B-B' (Cutoff Wall Only).

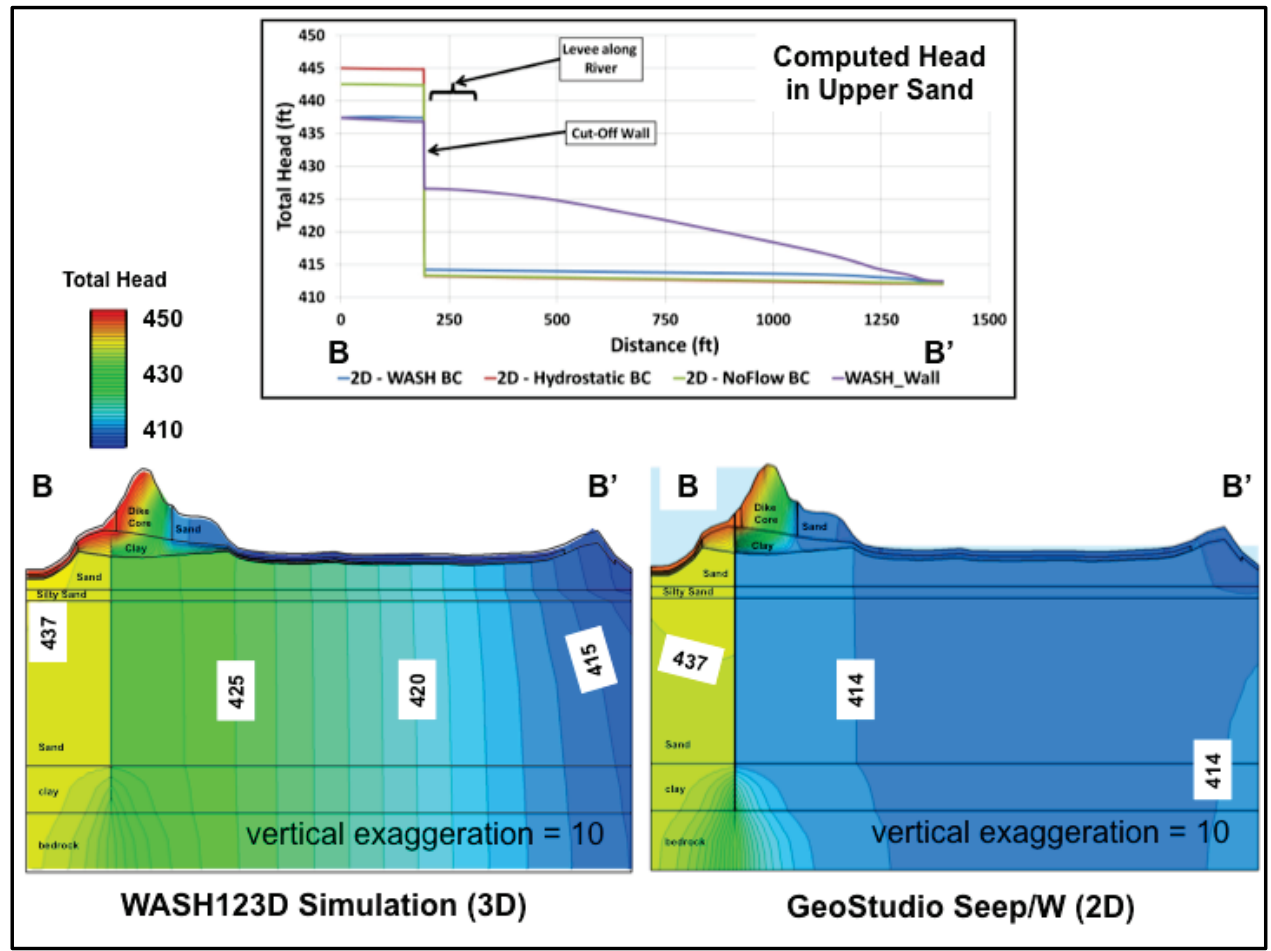

\section{Relief Wells Only}

The Relief Wells Only models differ from the Existing Condition models by including a set of partially penetrating relief wells lining up along the river and tributary to reduce groundwater heads and associated seepage issues. Figure 10 provides a plan view representation of the computed groundwater heads in the upper sand aquifer directly below the surface clay from the 3D Relief Wells Only model. End effects between and around the relief wells are evident. 
Figure 10. Computed total head distribution in upper sand aquifer from the 3D model (Relief Wells Only).

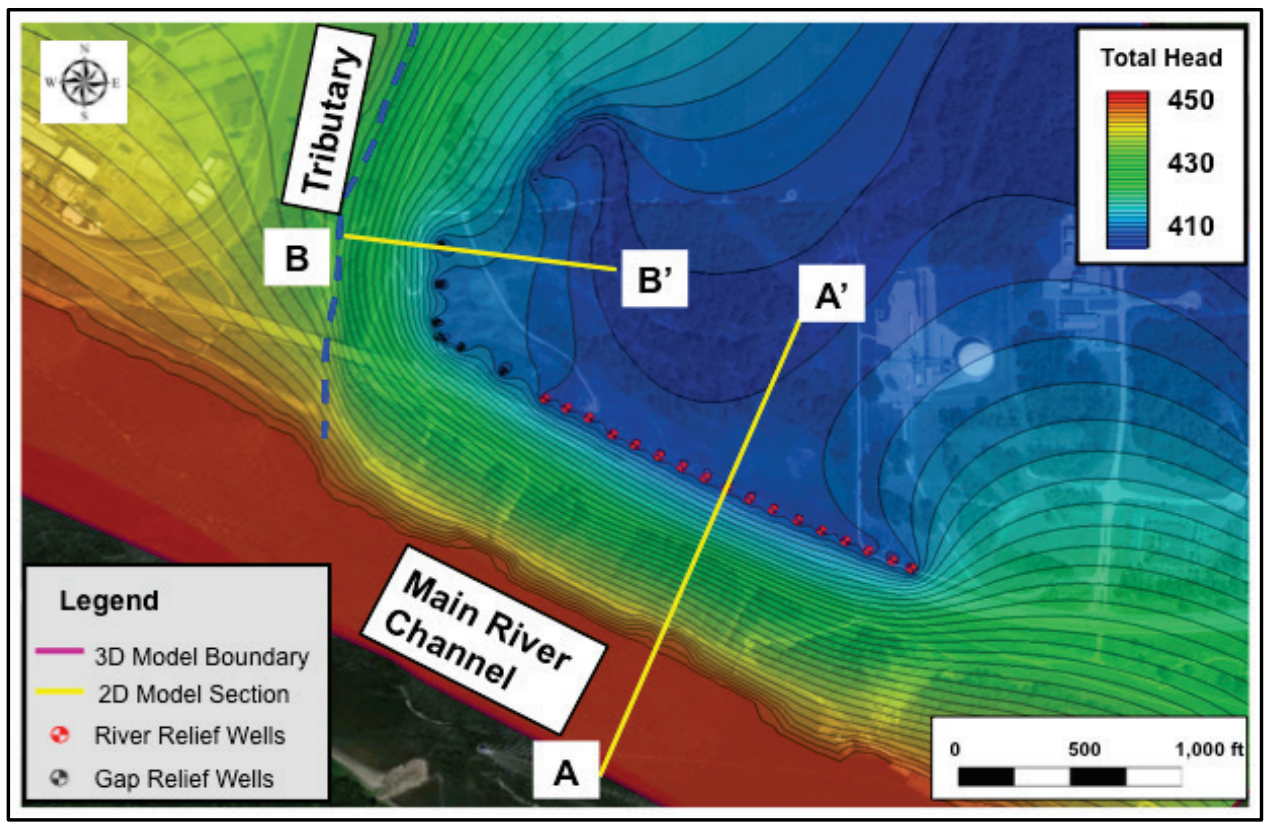

Figure 11 compares the simulated groundwater heads in the 2D and $3 \mathrm{D}$ models at Section A-A' in this scenario. As shown on top of Figure 12, the computed heads in the upper sand unit from the 2D model were reasonably consistent regardless of the boundary conditions applied. While the 3D model did compute slightly higher groundwater heads upstream and downstream of the relief well, these differences were small and likely due to the end effects around and between the relief wells.

Figure 11. Comparison of total head distribution: 2D cross-sectional vs. 3D at Section A-A' (Relief Wells Only).

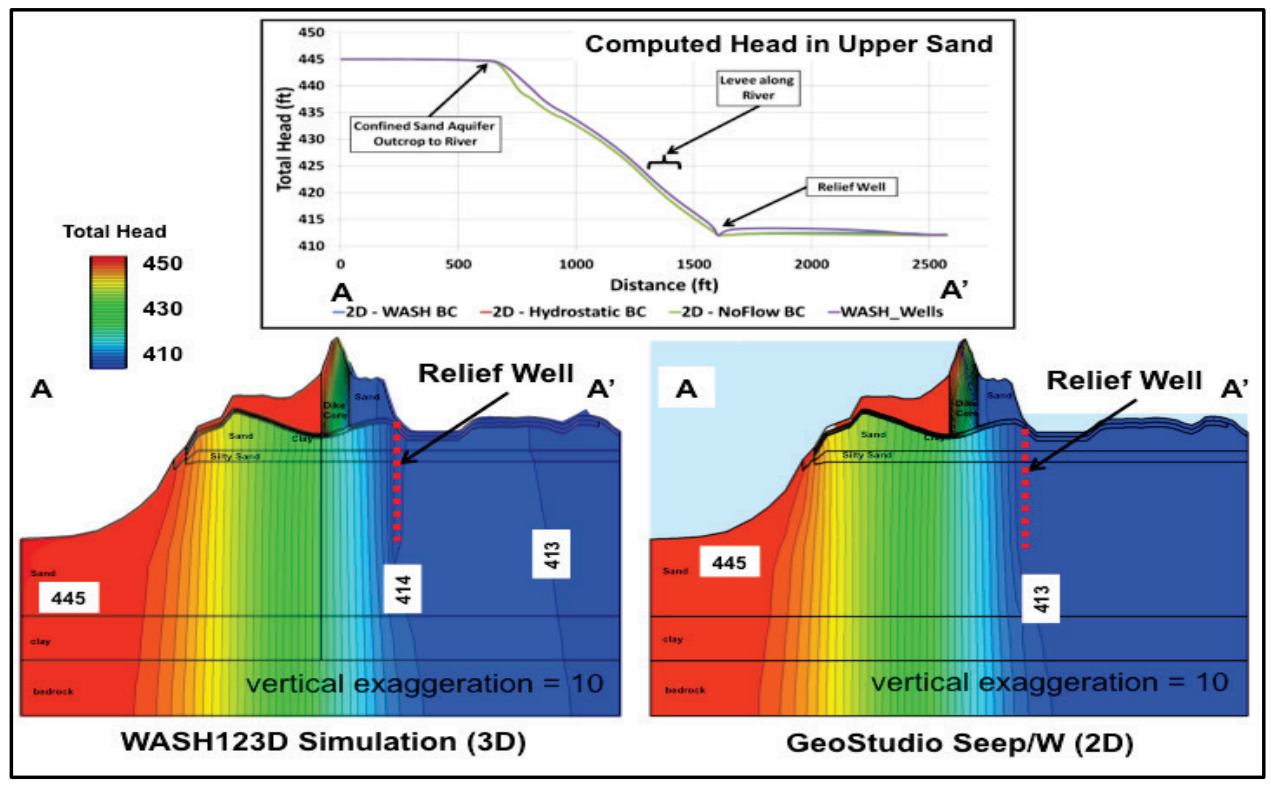


Figure 12. Comparison of total head distribution: 2D cross-sectional vs. 3D at Section B-B' (Relief Wells Only).

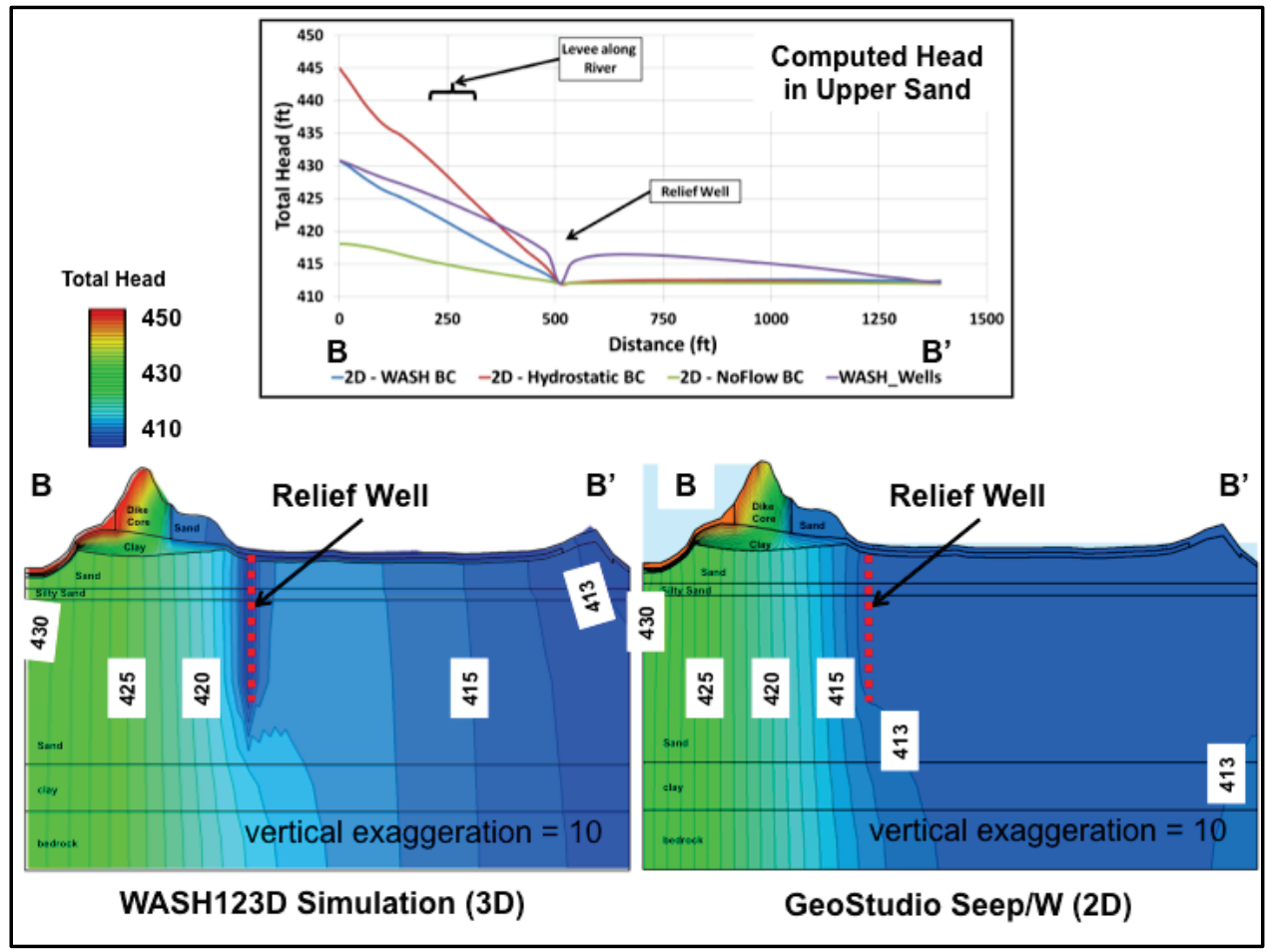

\section{Cutoff Wall and Relief Wells}

The last models considered accounted for both the cutoff wall and the relief wells described previously. Figure 13 provides a plan-view representation of the computed groundwater heads in the upper sand aquifer from the $3 \mathrm{D}$ model. Although end effects around the cutoff wall and through the gap were mitigated, the head contours showed that these effects have not been completely eliminated.

Figure 14 compares the simulated groundwater heads in the $2 \mathrm{D}$ and $3 \mathrm{D}$ models at Section A-A' in this wall-and-wells scenario. The computed heads from the 2D model at Section A-A' were not sensitive to the three sets of boundary conditions applied to the 2D model in this study, as shown at top of Figure 14. Moreover, the 2D and the 3D model results were comparable, which seems to indicate that the combination of cutoff wall and relief wells along the river sufficiently reduces the end effects at Section A-A'. However, note that the end effects around the cutoff wall and relief wells becomes more pronounced east of Section A-A' toward the end of the cutoff wall, as seen in Figure 13. 
Figure 13. Computed total head distribution in upper sand aquifer from the 3D model (Cutoff Wall and Relief Wells).

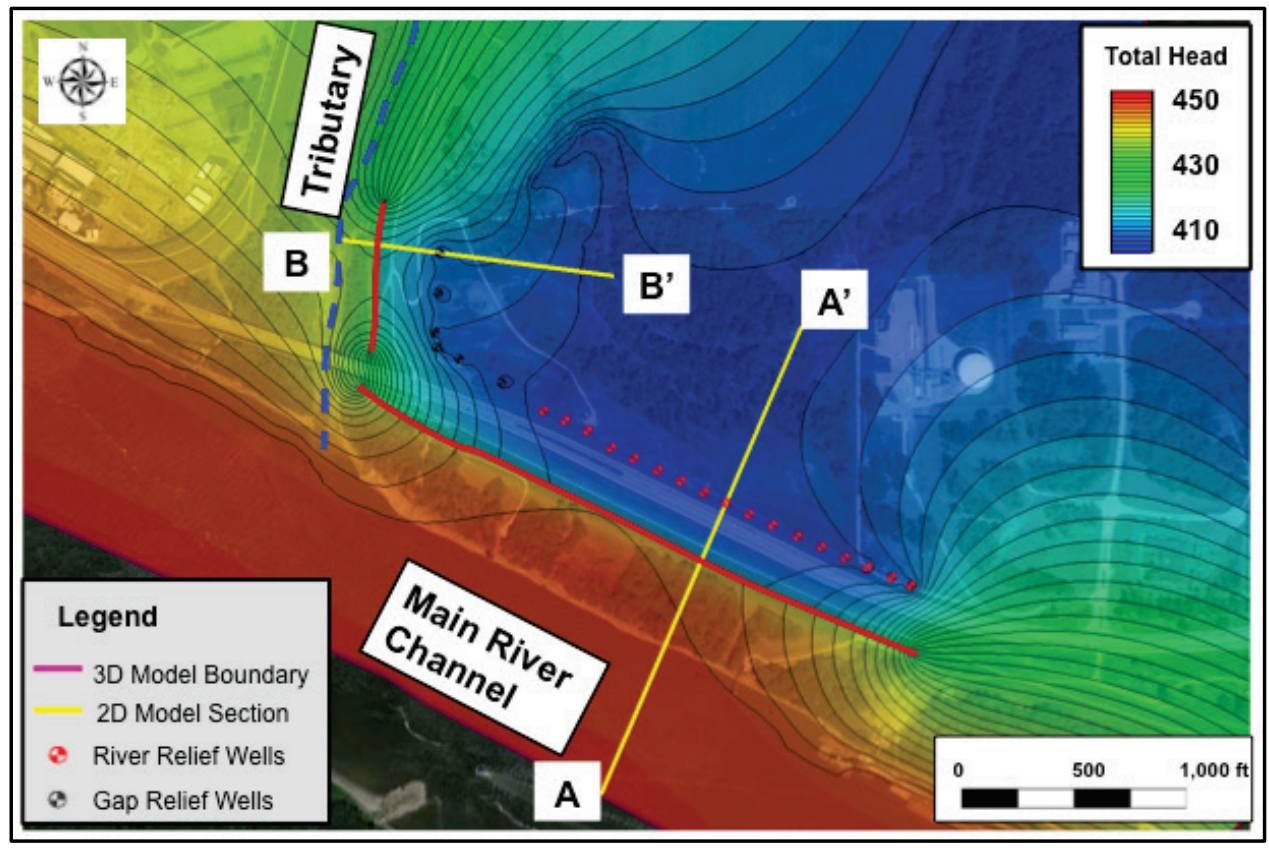

Figure 14. Comparison of total head distribution: 2D cross-sectional vs. 3D at Section A-A' (Cutoff Wall and Relief Wells).

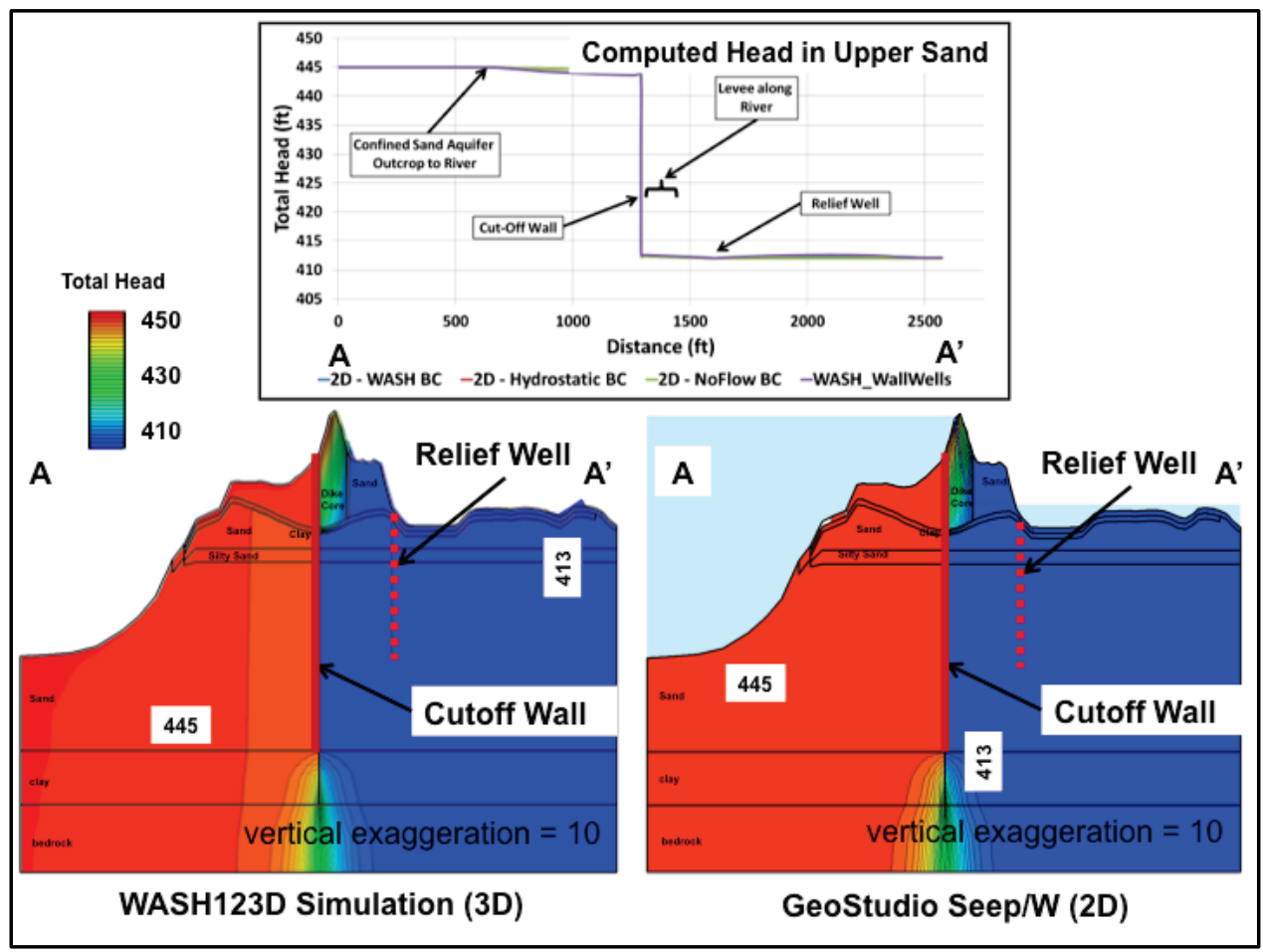


Figure 15 compares the simulated groundwater heads in the $2 \mathrm{D}$ and $3 \mathrm{D}$ Cutoff Wall and Relief Wells models at Section B-B'. The results of these simulations show similar attributes to those seen in the Cutoff Wall Only and Relief Wells Only simulations. The cone of depression simulated in the 3D model was more pronounced as seen at Section B-B' in the Relief Well Only simulations while west (left) boundary exhibits similar variations to that seen in the Cutoff Wall Only simulation (top, Figure 9). The combined effect of the cutoff wall and relief wells results in computed heads down gradient of the cutoff wall that were up to $5 \mathrm{ft}$ greater in the $3 \mathrm{D}$ model than those in the $2 \mathrm{D}$ model, and the localized effect of the relief well was better defined in the $3 \mathrm{D}$ model.

Figure 15. Comparison of total head distribution: 2D cross-sectional vs. $3 D$ at Section B-B' (Cutoff Wall and Relief Wells).

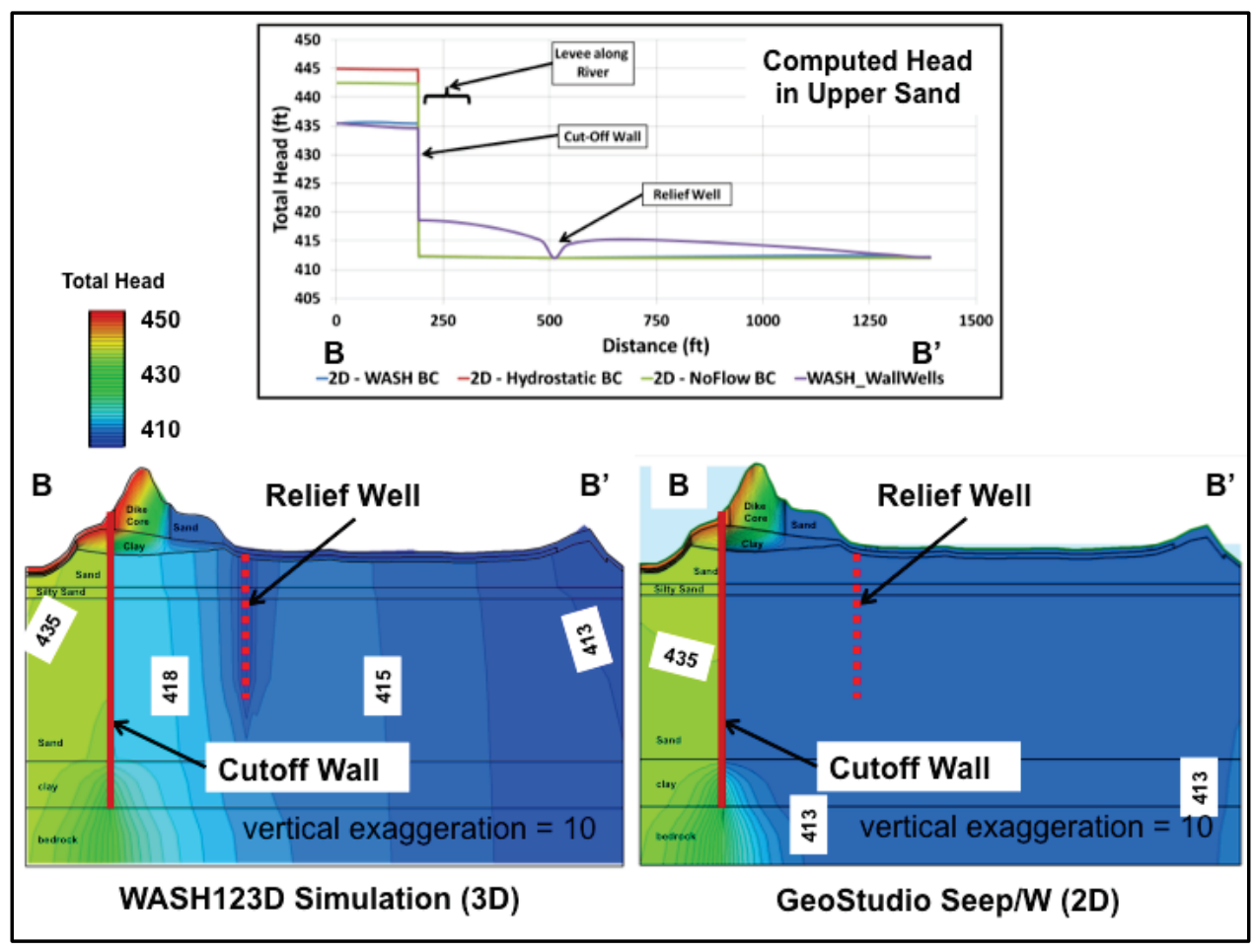




\section{Model Comparison (2D Plan-View)}

As expected, the $2 \mathrm{D}$ plan-view model compares reasonably well to the $3 \mathrm{D}$ model in areas where flow is generally horizontal and where the boundary conditions are similar. In areas where vertical flow is significant or where the boundary conditions cannot be matched, the two models differ. Here, the two models are examined by comparing the overall plan-view head contour map, heads computed at each of the two cross sections described in the previous section, and the fluxes calculated at the relief wells to keep the heads at the required level (Cheng 2015).

\section{Existing Condition}

Figure 16 shows the results of the Existing Condition models at Section AA'. The results of the two models are quite similar because there was little vertical flow at this location, and the boundary conditions (main river channel and tributary) were easily applied to the $2 \mathrm{D}$ model in the same way as the $3 \mathrm{D}$ model.

Figure 16. Comparison of total head distribution: 2D Plan view vs. 3D comparison at Section A-A' (Existing Condition).

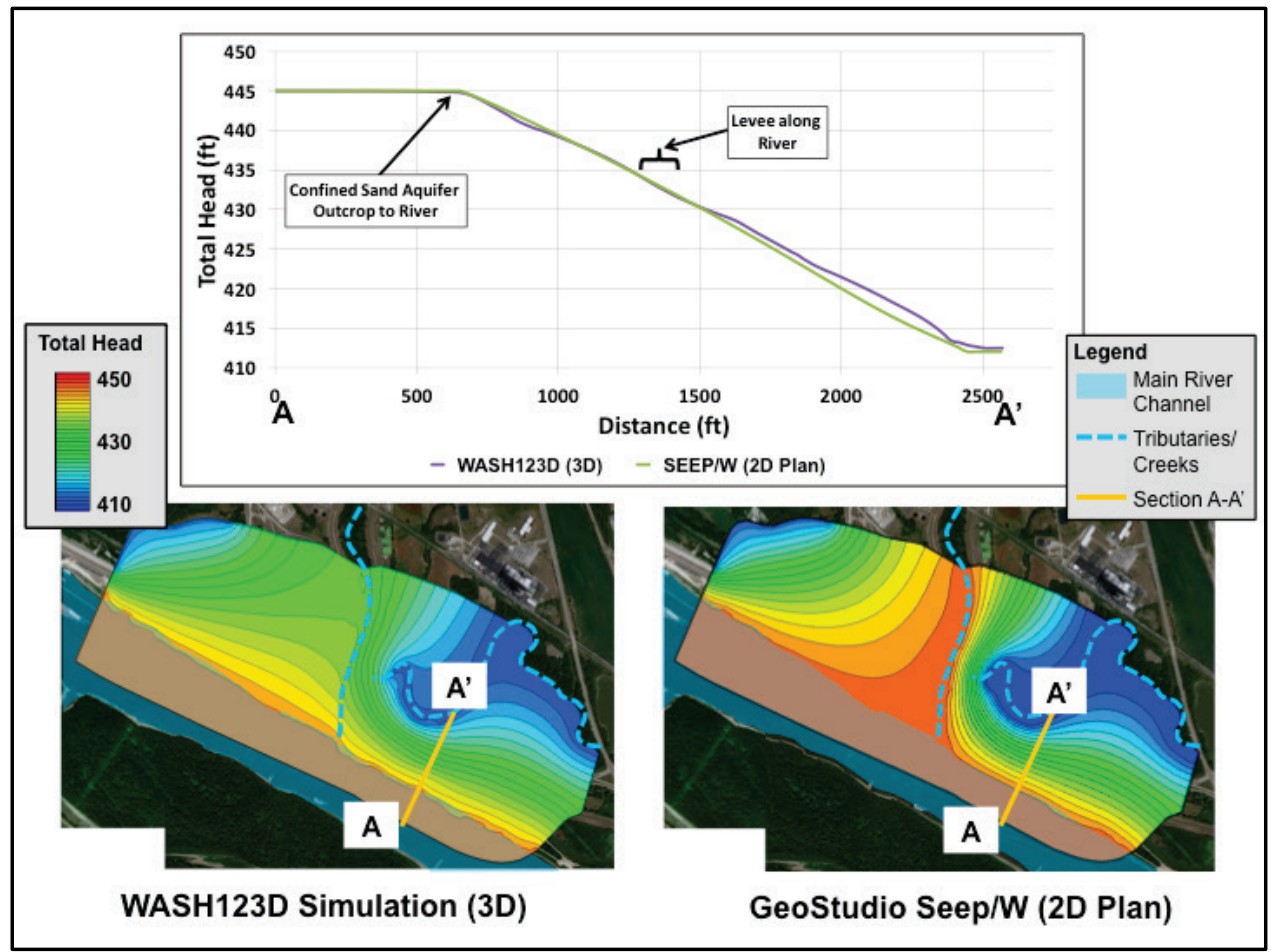


Figure 17 shows the Existing Condition models with the head comparison at Section B-B'. Note that this section extends into the area of the tributary where there existed vertical flow from the streambed to the groundwater system. In addition, the boundary condition that was applied to the surface of the $3 \mathrm{D}$ model was not easily replicated in the $2 \mathrm{D}$ model. The $3 \mathrm{D}$ model calculated a somewhat lower head in the sand unit under the tributary (top, Figure 17). With no other forces acting on the system, both models have a nearly linear reduction in head towards the tributary. While the tributary head was also applied to the surface of the $3 \mathrm{D}$ model, the effects in the sand could not be easily replicated in the $2 \mathrm{D}$ model. As a result, there was a small difference in where the head reaches the tributary head level (top, Figure 17).

Figure 17. Comparison of total head distribution: 2D Plan view vs. 3D comparison at Section B-B' (Existing Condition).

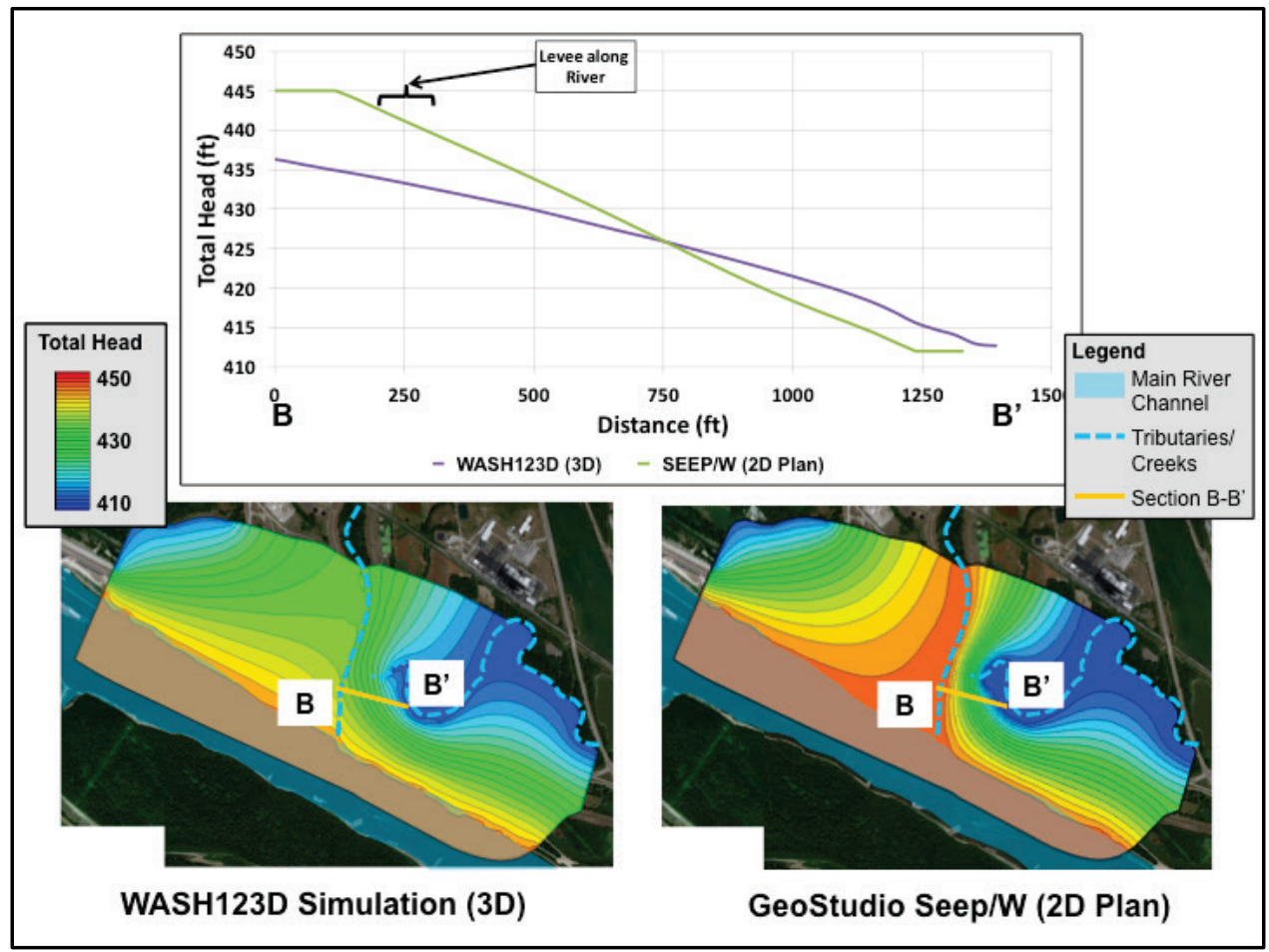

\section{Cutoff Wall Only}

Figure 18 shows the comparison at Section A-A' between the 2D plan-view model and the $3 \mathrm{D}$ model when a cutoff wall was present. The head drop across the cutoff wall was slightly greater for the 2D model (top, Figure 18). This is likely because the 2D model did not adequately catch the vertical flow toward the sand unit in the 3D model and the varied impact of the tributary head being applied to the surface of the $3 \mathrm{D}$ model. 
Figure 18. Comparison of total head distribution: 2D Plan view vs. 3D comparison at Section A-A' (Cutoff Wall Only).

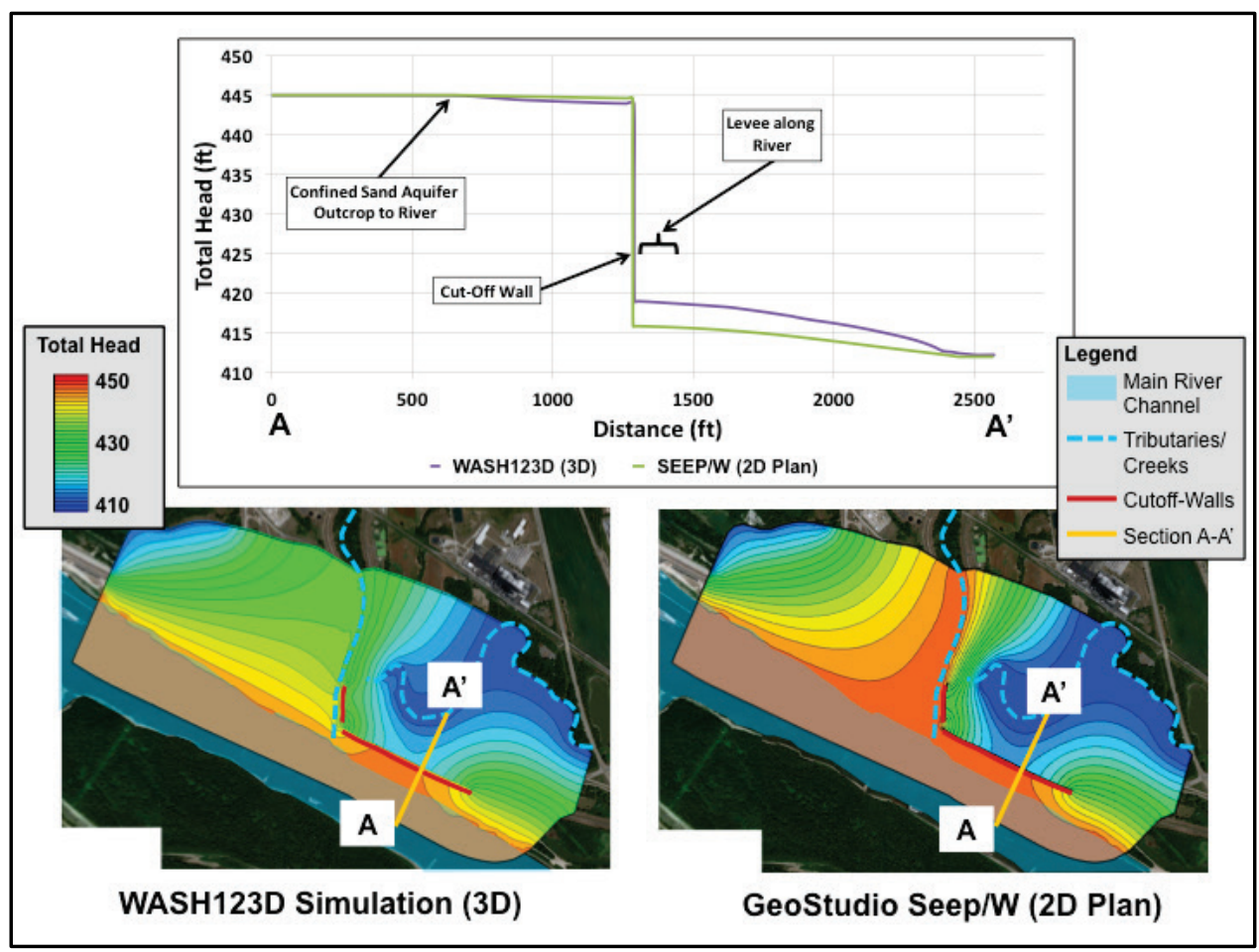

Figure 19 compares the 2D plan-view model and the 3D model at Section B-B' under the Cutoff Wall Only condition. The computed head of the west end of this cross section (i.e., head in the tributary) was somewhat higher for the 2D model because the boundary condition could not replicate the loss of head through the channel sediments. Head loss through the cutoff wall was again somewhat higher for the 2D model because the tributary boundary condition and some vertical flow in the $3 \mathrm{D}$ model were not captured in the $2 \mathrm{D}$ model.

\section{Relief Wells Only}

Figures 20 and 21 show the comparison between the 2D plan-view model and the 3D model at Sections A-A' and B-B', respectively, when relief wells were added to the system. At Section A-A' where flow was mostly horizontal, the two models produced very similar head results (top, Figure 20). At Section B-B', because there was significant vertical flow at the west end of this cross-section, the 2D model cannot correctly reproduce the heads resulting from the 3D model (as shown on top, Figure 21). 
Figure 19. Comparison of total head distribution: 2D Plan view vs. 3D comparison at Section B-B' (Cutoff Wall Only).

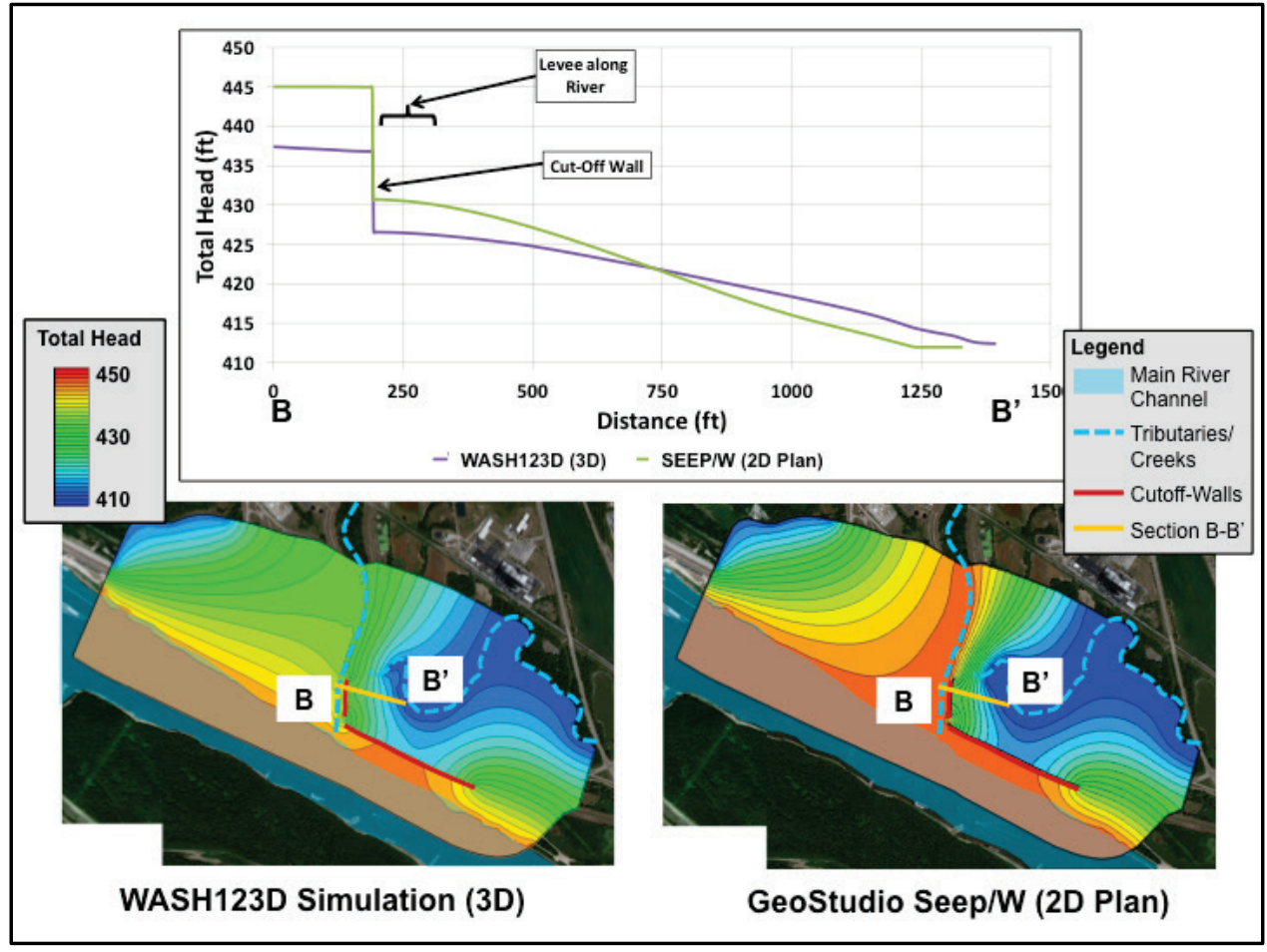

Figure 20. Comparison of total head distribution: 2D Plan view vs. 3D comparison at Section A-A' (Relief Wells Only).

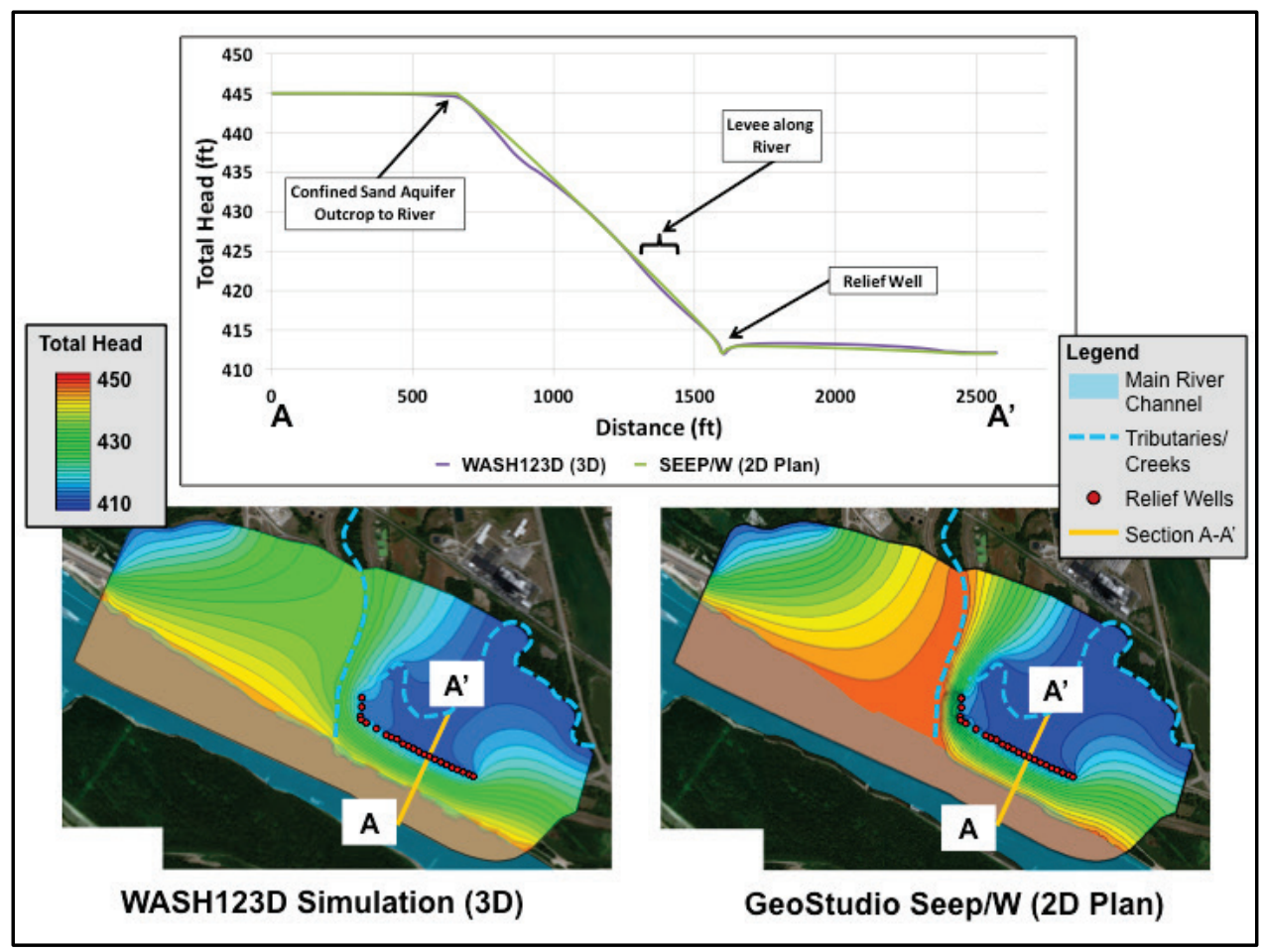


Figure 21. Comparison of total head distribution: 2D Plan view vs. 3D comparison at Section B-B' (Relief Wells Only).

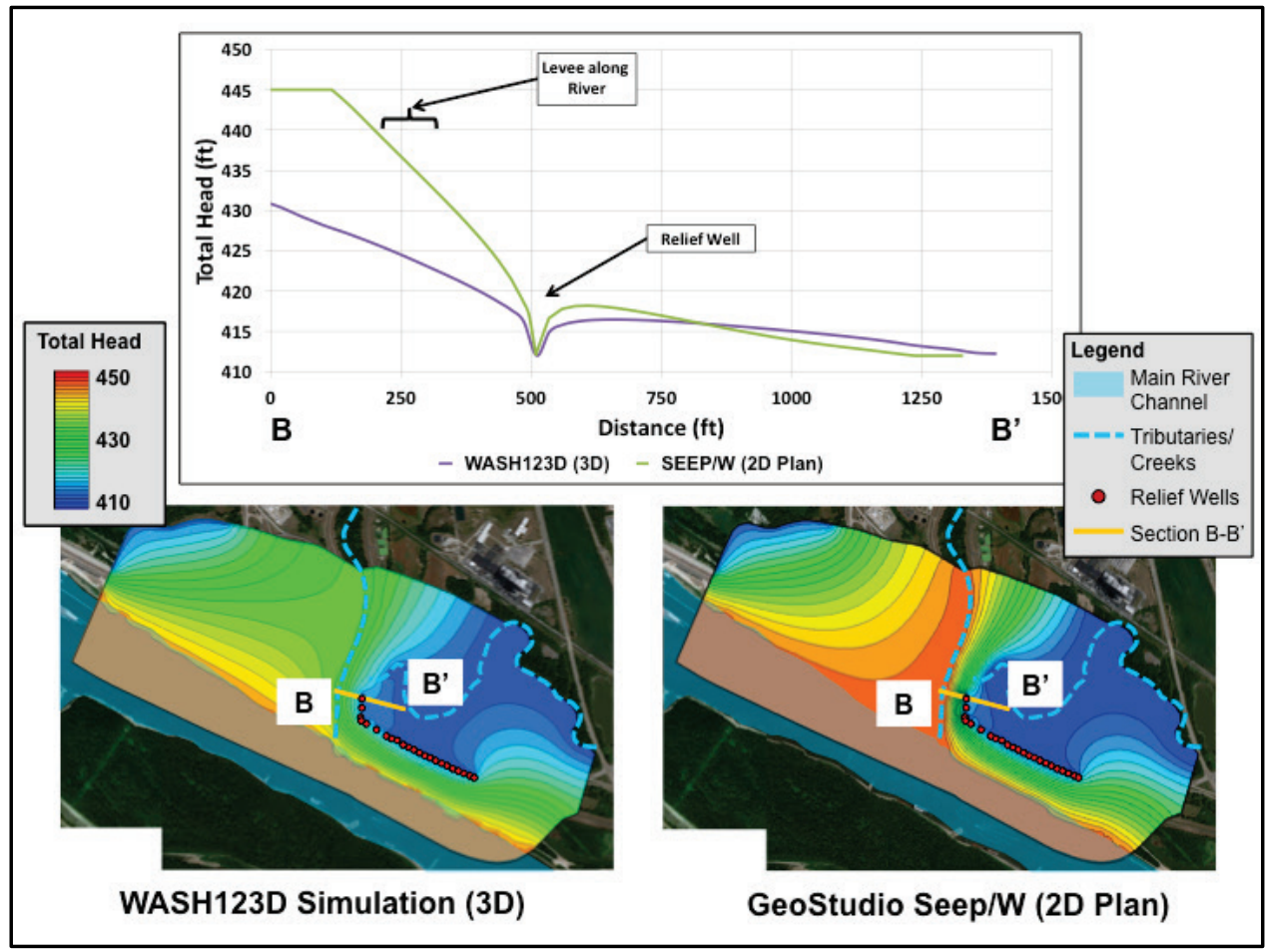

\section{Cutoff Wall and Relief Wells}

Figures 22 and 23 show the comparison between the 2D plan-view model and the 3D model at Sections A-A' and B-B', respectively, when both the cutoff wall and the relief wells were present. At Section A-A', there was little vertical flow, so the heads were quite similar (top, Figure 22). The head differences were significant at the west side of Section B-B' because of the significant vertical flow in the tributary (top, Figure 23).

\section{Comparisons of Fluxes at Relief Wells}

In the $3 \mathrm{D}$ model with relief wells incorporated, excess groundwater was removed from the model through these relief wells when heads exceeded the elevation of $412 \mathrm{ft}$ in the area of concern. While in the $2 \mathrm{D}$ plan-view model, the relief wells were incorporated as specified head points where the head was set to $412 \mathrm{ft}$. As the water levels never fell below $412 \mathrm{ft}$, the boundary condition applied to relief wells acted as sinks removing water from the groundwater system as expected. Figure 24 shows the locations of the relief wells with labels. Figures 25 and 26 show the comparison of relief well flux results of the 2D plan-view SEEP/W model and the $3 \mathrm{D}$ WASH123D model for each of the simulations with relief wells included. 
Figure 22. Comparison of total head distribution: 2D Plan view vs. 3D comparison at Section A-A' (Cutoff Wall and Relief Wells).

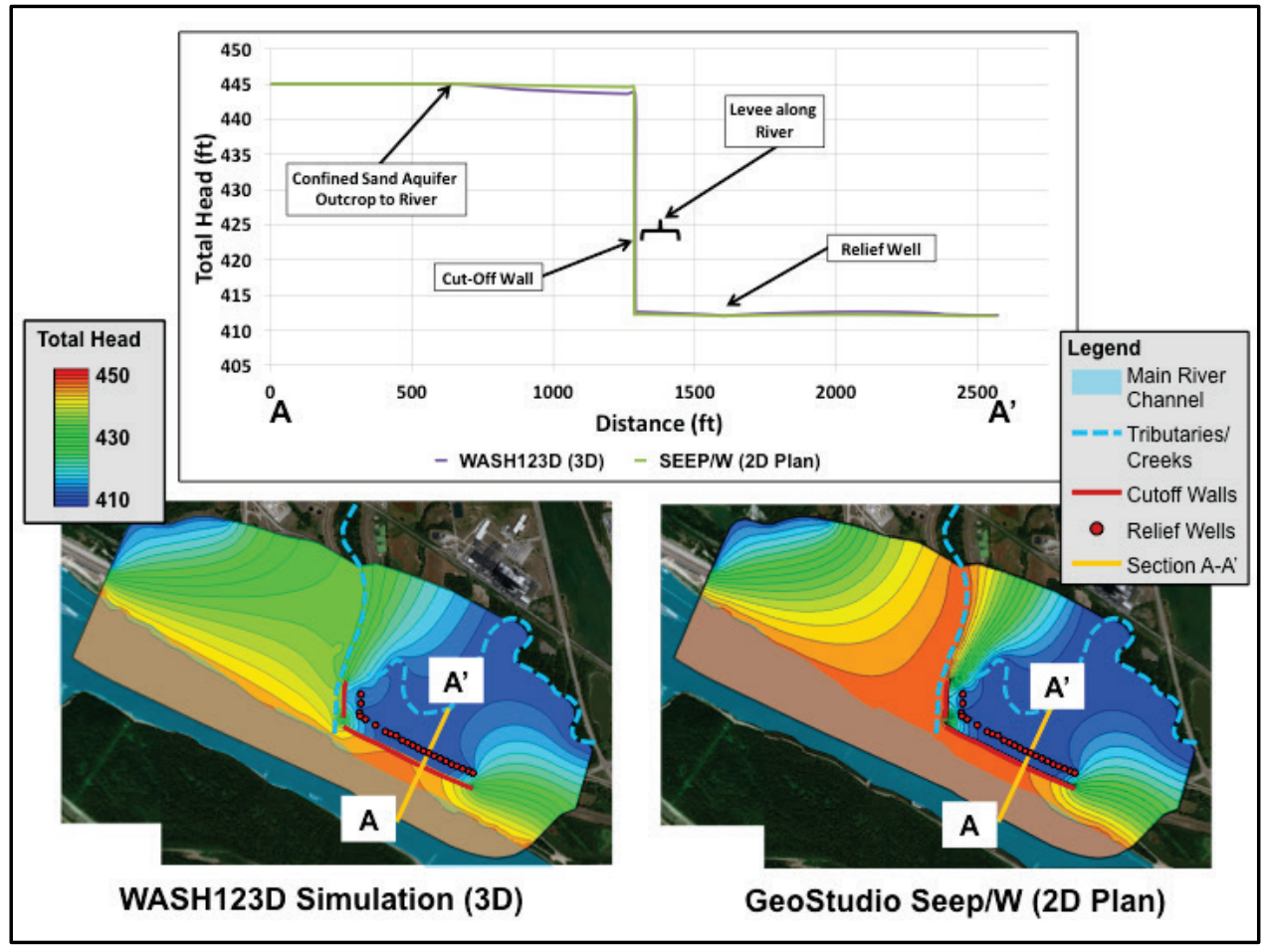

Figure 23. Comparison of total head distribution: 2D Plan view vs. 3D comparison at Section B-B' (Cutoff Wall and Relief Wells).

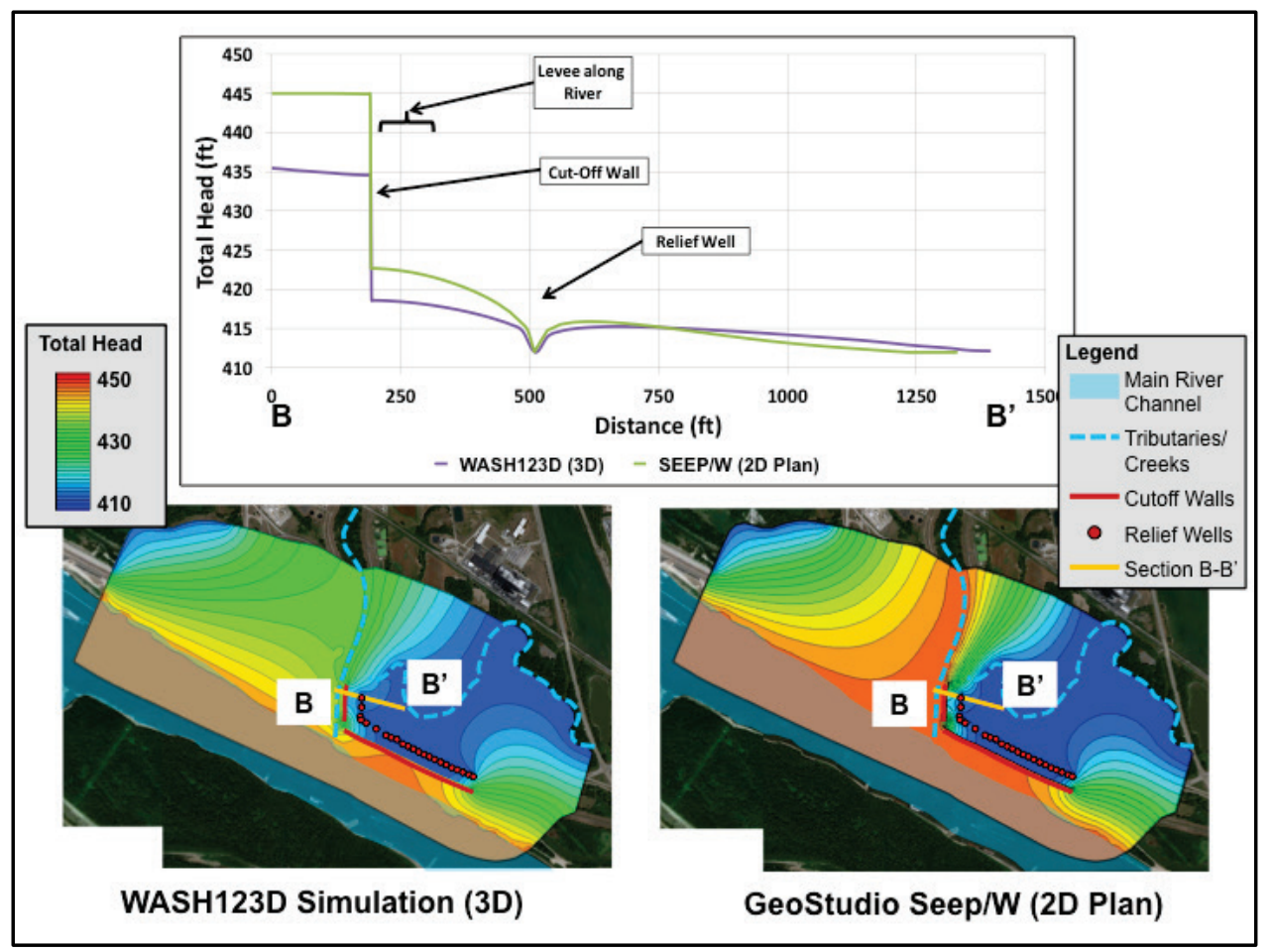


Figure 24. Relief Well locations.

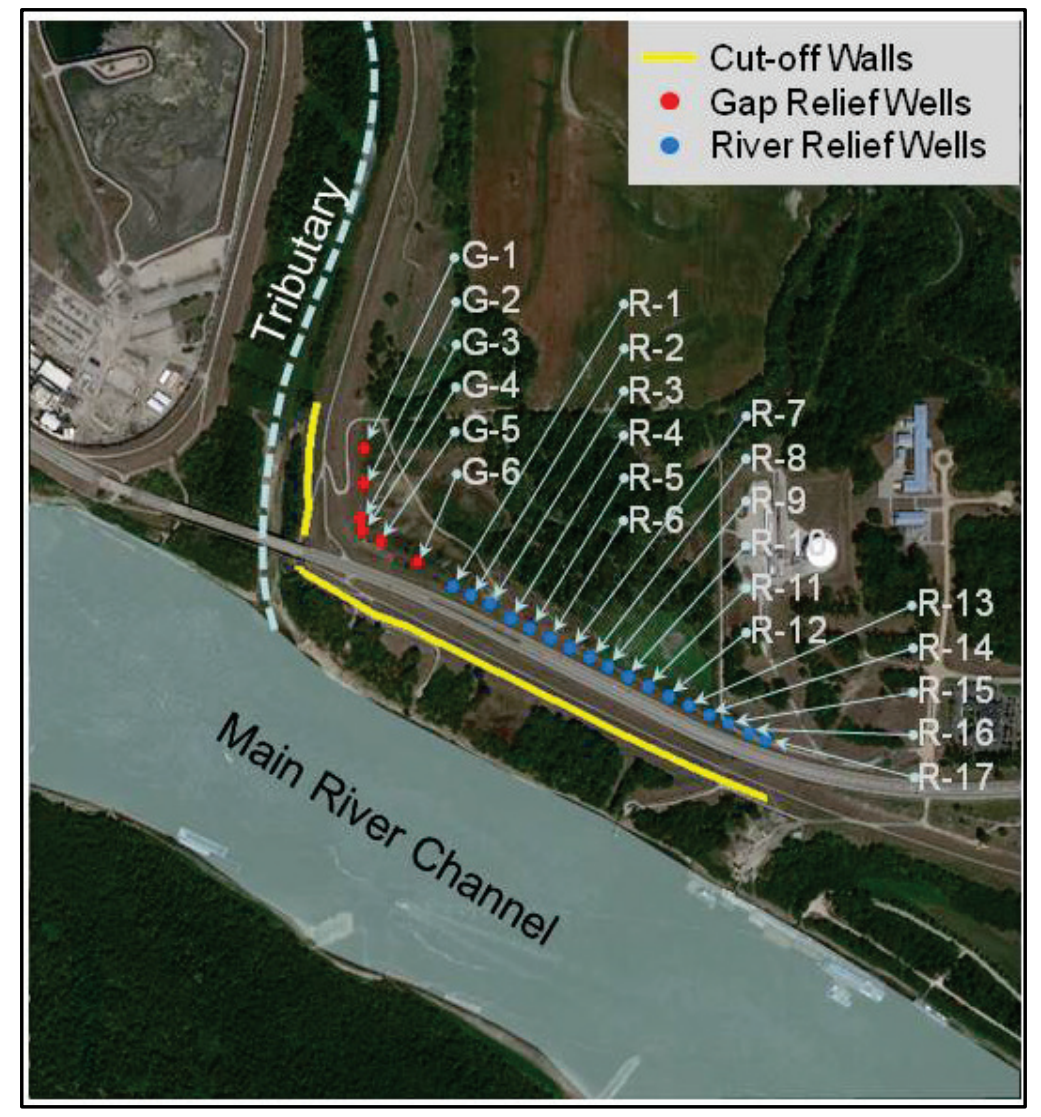

Figure 25. Comparison Relief Well fluxes without cutoff wall: 2D SEEP/W model vs. 3D WASH123D model.

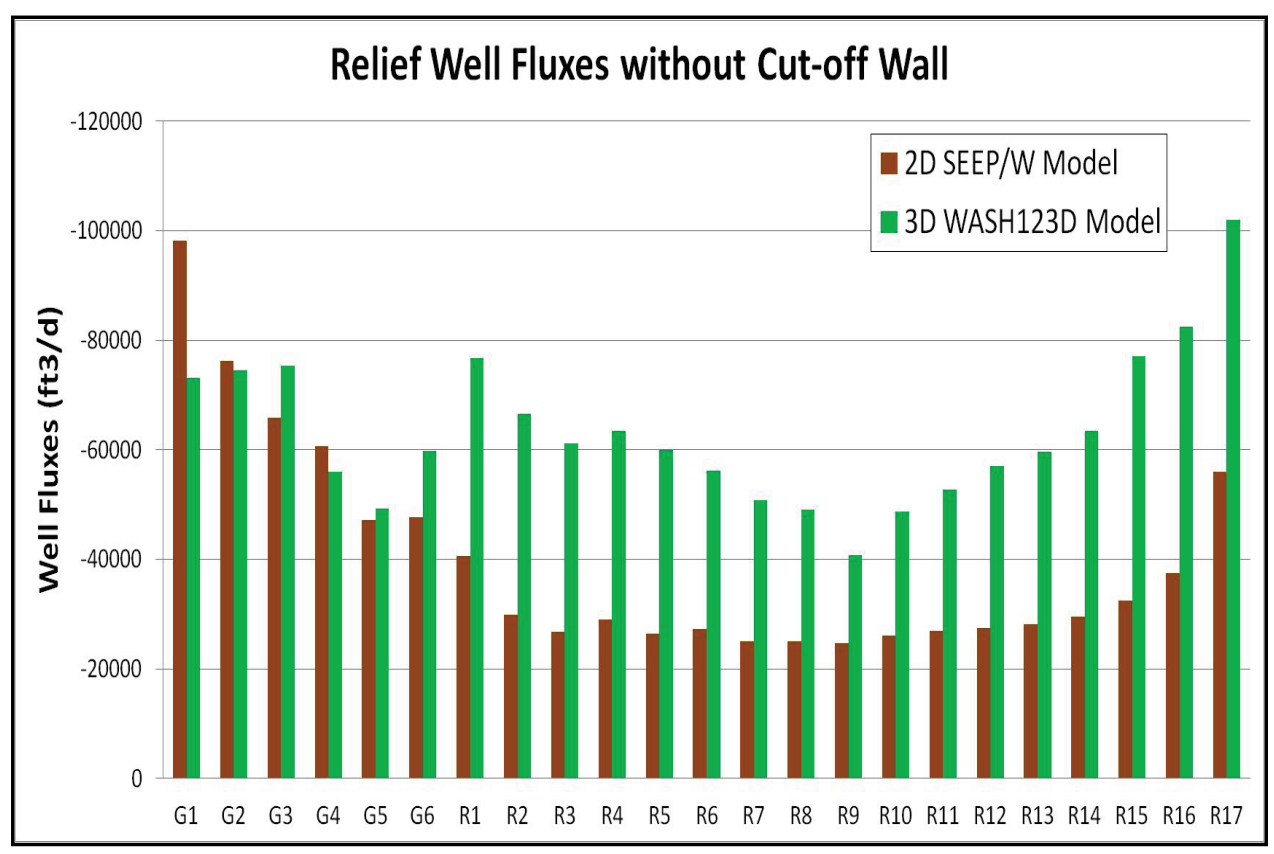


Figure 26. Comparison of Relief Well fluxes with cutoff wall: 2D SEEP/W model vs. 3D WASH123D model.

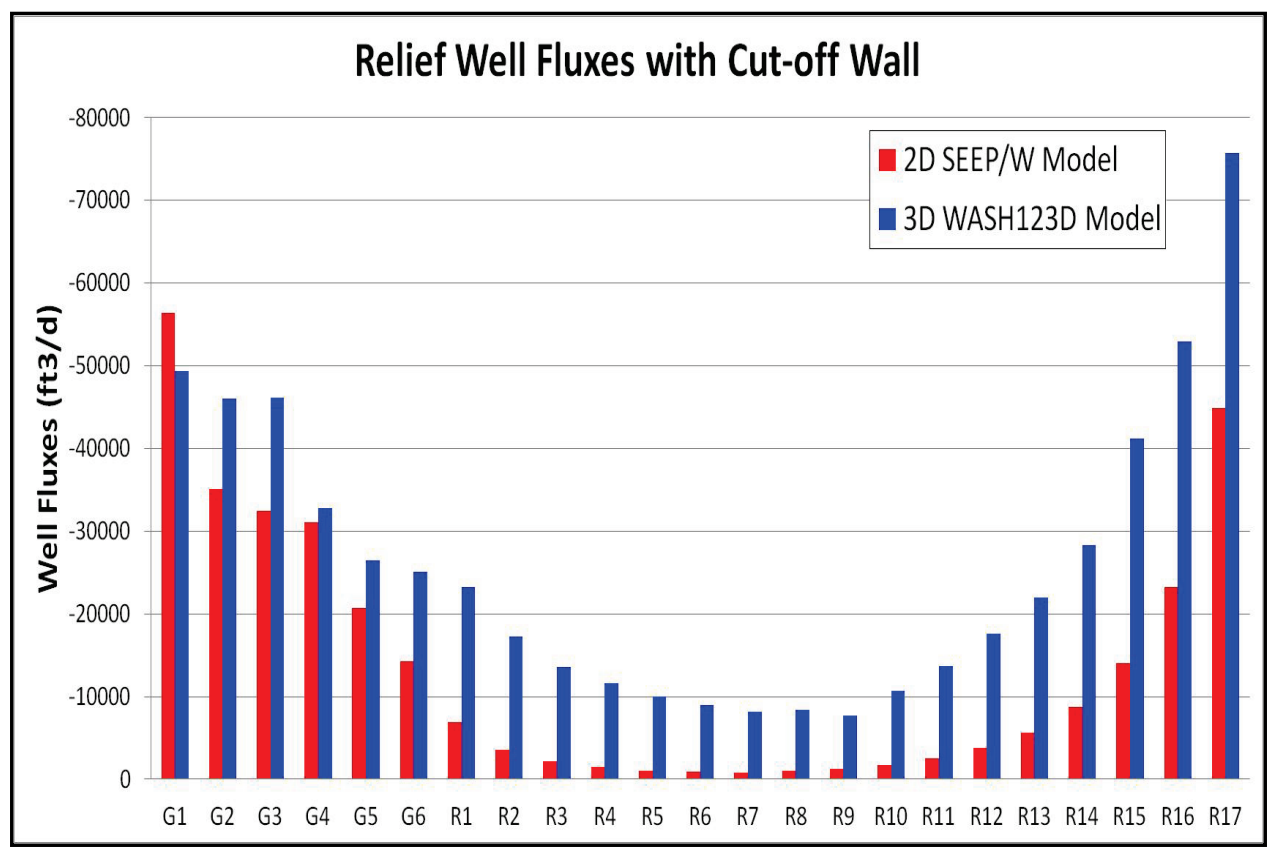

As shown in Figure 25, when there was no cutoff wall, relief well fluxes in the gap relief wells (red circle in Figure 24) were somewhat similar between the 2D SEEP/W and 3D WASH123D models with the exception at G1, where the computed relief well flux by the 2D model was approximately $25 \%$ more than that by the $3 \mathrm{D}$ model. In the river relief wells (blue circle in Figure 24), the 2D model underestimated the fluxes by approximately half.

When the cutoff wall was taken into account, the gap relief well fluxes were again somewhat similar, though the differences at G2 and $\mathrm{G}_{3}$ are greater (Figure 26). Again, the 2D model calculated lower fluxes at the river relief wells when compared with the $3 \mathrm{D}$ model. At some river relief wells (e.g., $\mathrm{R} 1$ through R13) the fluxes calculated by the $2 \mathrm{D}$ model were lower than $25 \%$ of those calculated by the $3 \mathrm{D}$ model, showing significant differences.

These results did not make sense intuitively. For example, it had been expected that the $2 \mathrm{D}$ model would be less able to reproduce fluxes at the gap relief wells than the river relief wells because the 2D model cannot reproduce downward vertical flow from the tributary and the head results were significantly different in this area. It had also been expected that the inclusion of the cutoff wall would make the $2 \mathrm{D}$ and $3 \mathrm{D}$ results more similar because it would cut the relief wells off from some parts of the model where head results varied between the two models. 
Because these results did not show the expected results, an additional 3D WASH123D model was built to simulate only the upper sand layer to confirm the 2D SEEP/W model was set up adequately. The model had only two layers of elements, and boundary conditions were applied exactly as they had been applied on the 2D plan-view model. Every effort was made to ensure that this additional $3 \mathrm{D}$ model was set up exactly as the $2 \mathrm{D}$ model. The purpose was to ensure that both models were reporting fluxes consistently. As shown in Figure 27, this additional 3D model reproduced the 2D results almost perfectly, indicating that all differences in Figures 25 and 26 were due to inherent differences in the $2 \mathrm{D}$ and $3 \mathrm{D}$ model setup and assumptions.

Figure 27. Comparison of Relief Well fluxes: 2D SEEP/W model vs. simplified 3D WASH123D model.

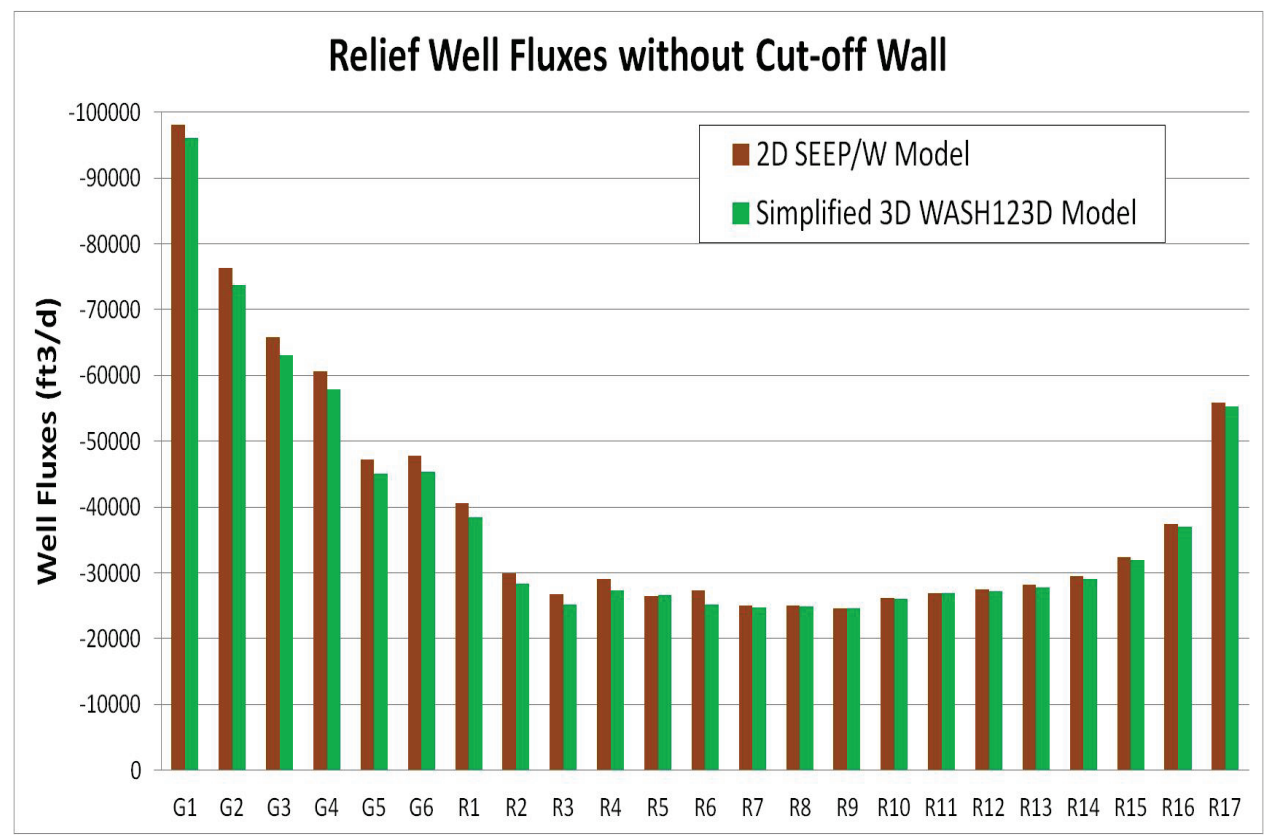

Some of the assumptions and differences between the $2 \mathrm{D}$ and $3 \mathrm{D}$ models were as follows.

- Vertical flow was not simulated in the 2D model.

- Surficial boundary conditions (tributary and stream) were applied to the ground surface in the $3 \mathrm{D}$ model, which allowed surface water to percolate through the streambed material and other units before reaching the upper sand unit. In the $2 \mathrm{D}$ model, however, the same boundary conditions were applied to the top of the upper sand directly.

- In the 3D model, some of the flow to the relief wells came from overlying and underlying units. This did not occur in the 2D model. 
- Recharge was added to the 3D model and was allowed to percolate through the overlying layers to the upper sand unit. No recharge was applied to the 2D plan-view model. It was assumed that only a negligible amount of water would pass through the overlying confining unit.

- Upper and lower elevations for the upper sand in the 3D model were based on interpolations of boring data and were allowed to vary from element to element. The 2D model allowed the input of upper and lower sand elevations at three $(\mathrm{x}, \mathrm{y})$ locations in the model domain. Those three points were then applied as a plane to the top and bottom of the model. This means that the thickness of the aquifer modeled was different at almost every location in the two models.

The fact that the results of the flux comparison between the 2D plan-view and $3 \mathrm{D}$ models did not turn out as expected illustrates an important point. In some cases the system can be more complex than expected, and it cannot always be foreseen what will be the dominant impact of the 2D simplifications. As shown in the analysis above, the 2D model may be sufficient for estimating the fluxes from the gap relief wells, but it would greatly underestimate the fluxes required to keep the water levels low near the river relief wells. Unfortunately, this could not be known before the $3 \mathrm{D}$ model was built. Great care must be taken when budget and schedule constraints force the use of a 2D plan-view model for a $3 \mathrm{D}$ system. Although sensitivity analyses can potentially bound the results, they may not be able to account for the complexities of the real world $3 \mathrm{D}$ system fully. For example, a pumping well in the vicinity of the area of concern may regionally impact the groundwater flow system, but a traditional 2D model may not incorporate it into the model. 


\section{Summary}

Table 2 summarizes the comparisons of each of the 2D models to the respective 3D model. Most of the Section A-A' models compare favorably to their respective $3 \mathrm{D}$ models. This is generally because the flow was parallel to the cross section and because boundary conditions were easily applied to the simplified 2D models. Nevertheless, end effects on the cutoff wall did cause some differences between the $2 \mathrm{D}$ and the $3 \mathrm{D}$ models at Section A-A' when the cutoff wall was installed without relief wells. Conversely, the $2 \mathrm{D}$ models did not reproduce the $3 \mathrm{D}$ results at Section BB', where the flow was not always parallel to the cross sections and the boundary conditions were not easily applied due to complexities of the system. Some of the 2D models overpredicted heads, and the others underpredicted heads. The $2 \mathrm{D}$ plan-view model was not able to reproduce the relief well fluxes along the river, and it was not adequate to use a 2D plan-view model to predict the results.

The results of this analysis indicate several strengths and weakness of both the $2 \mathrm{D}$ and $3 \mathrm{D}$ modeling approaches, stated as follows.

- The 2D models are easier to construct and require less computational time for each simulation. For the models presented in this document, run times for the $2 \mathrm{D}$ model were several seconds while it took the $3 \mathrm{D}$ model up to 15 minutes to complete a simulation on the same computer.

- An inherent assumption with any 2D model is that the cross section (vertical or horizontal) is cut parallel to the flow path. However, complex geologic (semiconfining units beneath river boundaries, discontinuities in confining materials, etc.) and topographic (river confluences, dams, etc.) features are likely to result in complex $3 \mathrm{D}$ flow fields in the real world. Consequently, it may be difficult or even impossible to define an appropriate 2D cross-sectional model accurately.

- Because individual cross sections are generally used to evaluate both with and without project conditions, the flow field resulting under with project conditions may significantly differ from the Existing Condition. If the changes in flow field violate the inherent $2 \mathrm{D}$ flow path assumption, the utility of a 2D model will be limited and can lead to erroneous conclusions. 
- Physics-based 3D models, such as WASH123D, are better able to simulate geologic, topographic, and project-induced complexities in the groundwater flow fields. As seen in both the cross-sectional and plan-view model comparisons presented, the simplifications necessary for the 2D model may result in either over- or underpredicting uplift pressures and seepage gradients.

- Because the computed groundwater heads directly correlate to the estimation of the FoS, failure to properly simulate the flow fields could lead to an inaccurate calculation of the FoS (Cheng et al. 2014) provided by different design alternatives.

Table 2. Result Summary.

\begin{tabular}{|c|c|c|c|c|c|}
\hline \multirow[b]{3}{*}{ Scenario } & \multirow[b]{3}{*}{$\mathrm{XS}^{1}$} & \multicolumn{3}{|c|}{ 2D Cross-Sectional Model } & \multirow[b]{3}{*}{ 2D Plan-View Model } \\
\hline & & \multicolumn{3}{|c|}{ Boundary Condition } & \\
\hline & & From WASH & Hydrostatic & No Flow & \\
\hline \multirow{2}{*}{$\begin{array}{l}\text { Existing } \\
\text { Condition }\end{array}$} & $A-A^{\prime}$ & $\mathrm{SH}^{2}$ & $\mathrm{SH}$ & $\mathrm{SH}$ & $\mathrm{SH}$ \\
\hline & B-B' & $\mathrm{SH}$ & $\mathrm{UH}^{3}: 9 \mathrm{ft}$ higher & UH: $12 \mathrm{ft}$ lower & $\begin{array}{l}\text { UH: } 8 \text { ft higher; } \\
\text { DH4: slightly lower }\end{array}$ \\
\hline \multirow{2}{*}{$\begin{array}{l}\text { Cutoff Wall } \\
\text { Only }\end{array}$} & $A-A^{\prime}$ & $\begin{array}{l}\text { HUW5: similar; HDW6: } \\
5 \mathrm{ft} \text { lower }\end{array}$ & $\begin{array}{l}\text { HUW: similar; HDW: } 5 \\
\text { ft lower }\end{array}$ & $\begin{array}{l}\text { HUW: similar; HDW: } 5 \\
\text { ft lower }\end{array}$ & $\begin{array}{l}\text { HUW: similar; } \\
\text { HDW: } 3 \text { ft lower }\end{array}$ \\
\hline & B-B' & $\begin{array}{l}\text { HUW: similar; HDW: } \\
14 \mathrm{ft} \text { lower }\end{array}$ & $\begin{array}{l}\text { HUW: } 5 \mathrm{ft} \text { higher; HDW: } \\
14 \mathrm{ft} \text { lower }\end{array}$ & $\begin{array}{l}\text { HUW: } 7 \mathrm{ft} \mathrm{higher;} \\
\text { HDW: } 14 \mathrm{ft} \text { lower }\end{array}$ & $\begin{array}{l}\text { HUW: } 8 \mathrm{ft} \mathrm{higher;} \\
\text { HDW: } 4 \mathrm{ft} \mathrm{higher;} \\
\text { DH: slightly lower }\end{array}$ \\
\hline \multirow[b]{2}{*}{$\begin{array}{l}\text { Relief Wells } \\
\text { Only }\end{array}$} & $A-A^{\prime}$ & $\mathrm{SH}$ & $\mathrm{SH}$ & $\mathrm{SH}$ & SH; GRWF7: similar \\
\hline & B-B' & $\begin{array}{l}\text { CD8: not visible; } \\
\text { HNW9: } \\
\text { underpredicted }\end{array}$ & $\begin{array}{l}\text { UH: } 15 \mathrm{ft} \text { higher; CD: } \\
\text { not visible; HNW: } \\
\text { underpredicted }\end{array}$ & $\begin{array}{l}\text { UH: } 12 \text { ft lower; CD: } \\
\text { not visible; HNW: } \\
\text { underpredicted }\end{array}$ & $\begin{array}{l}\text { UH: } 14 \mathrm{ft} \text { higher; } \\
\text { RRWF10: 50\% lower }\end{array}$ \\
\hline \multirow{2}{*}{$\begin{array}{l}\text { Cutoff Wall } \\
\text { and Relief } \\
\text { Wells }\end{array}$} & $A-A^{\prime}$ & $\mathrm{SH}$ & $\mathrm{SH}$ & $\mathrm{SH}$ & $\begin{array}{l}\text { SH; } \\
\text { GRWF: a bit lower }\end{array}$ \\
\hline & B-B' & $\begin{array}{l}\text { HUW: similar; HDW: } 7 \\
\text { ft lower; CD: not } \\
\text { visible; HNW: } \\
\text { underpredicted }\end{array}$ & $\begin{array}{l}\text { HUW: } 10 \mathrm{ft} \text { higher; } \\
\text { HDW: } 7 \mathrm{ft} \text { lower; CD: } \\
\text { not visible; HNW: } \\
\text { underpredicted }\end{array}$ & $\begin{array}{l}\text { HUW: } 7 \mathrm{ft} \text { higher; } \\
\text { HDW: } 7 \mathrm{ft} \text { lower; CD: } \\
\text { not visible; HNW: } \\
\text { underpredicted }\end{array}$ & $\begin{array}{l}\text { UH: } 10 \mathrm{ft} \mathrm{higher;} \mathrm{HDW:} \\
4 \mathrm{ft} \text { higher; RRWF: } \\
25 \% \text { and lower (R1 - } \\
\text { R13) }\end{array}$ \\
\hline
\end{tabular}

${ }^{1} \mathrm{XS}=$ Cross section; ${ }^{2} \mathrm{SH}=$ Similar heads; ${ }^{3} \mathrm{UH}=$ Upstream heads;

${ }^{4} \mathrm{DH}=$ Downstream heads; ${ }^{5} \mathrm{HUW}=$ Heads upstream of cutoff wall;

6HDW = Heads downstream of cutoff wall; ${ }^{7}$ GRWF = Gap relief well fluxes;

${ }^{8} \mathrm{CD}=$ Cone of depression; ${ }^{9 H N W}=$ Heads near relief wells; ${ }^{10} \mathrm{RRWF}=$ River relief well fluxes.

The configuration of the groundwater problem being tackled and the design alternatives being simulated need to be carefully evaluated during the model selection process. In cases where groundwater flow fields are reasonably linear, a 2D model may be appropriate as a design level analysis tool. Unfortunately, the extent of variability due to $3 \mathrm{D}$ groundwater effects 
may not be well known during the model construction process. Due to this uncertainty, care must be taken to fully understand the conceptual groundwater flow patterns using the field data. If the potential exists for effects similar to those presented in the document, a 2D model may be acceptable for a screening-level analysis, but a 3D model may be necessary for a design-level analysis. 


\section{References}

Cheng, H.-P. 2015. Computing flow through well screens using an embedded well technique. ERDC/CHL CHETN-XI-4. http://acwc.sdp.sirsi.net/client/search/asset/ 1045249.

Cheng, H-P., K. D. Winters, S. M. England, and R. E. Pickett. 2014. Seepage-based factor of safety analysis using $3 D$ groundwater simulation results. ERDC/CHL CHETN-XI-2. Vicksburg, MS: U.S. Army Engineer Research and Development Center. http://acwc.sdp.sirsi.net/client/search/asset/1035965.

Geo-Slope. 2012. SEEP/W software users guide. Calgary, Canada: GEO-SLOPE International Ltd. http://www.hydrosys.net/myplus/bbs/table/hydrosys_doc/ upload/seep_manual.pdf.

U.S. Army Corps of Engineers. 2010. Emergency flood fight training manual. USACE Digital Library. U.S. Army Corps of Engineers.

http://cdm16021.contentdm.oclc.org/cdm/ref/collection/p16021coll11/id/1.

Yeh, G.-T., G. Huang, H.-P. Cheng, F. Zhang, H.-C. Lin, E. Edris, and D. Richards. 2006. A first-principle, physics-based watershed model: WASH123D. In Watershed Models, ed. V. P. Singh and D. K. Frevert, 211-244. Boca Raton, FL: CRC Press, Taylor and Francis Group. 


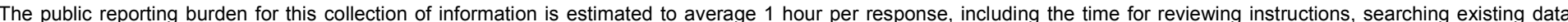

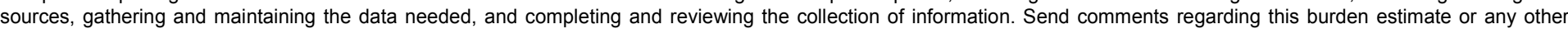

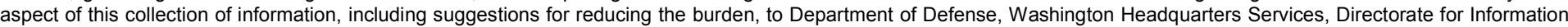

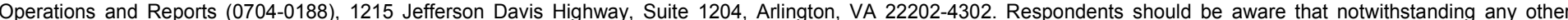
provision of law, no person shall be subject to any penalty for failing to comply with a collection of information if it does not display a currently valid OMB control number. PLEASE DO NOT RETURN YOUR FORM TO THE ABOVE ADDRESS.

\begin{tabular}{l|l|l}
$\begin{array}{l}\text { 1. REPORT DATE } \\
\text { June } 2016\end{array}$ & $\begin{array}{l}\text { 2. REPORT TYPE } \\
\text { Final Report }\end{array}$ & 3. DATES COVERED (FrOm - To)
\end{tabular}

\section{TITLE AND SUBTITLE}

5a. CONTRACT NUMBER

Seepage and Piping through Levees and Dikes using 2D and 3D Modeling Codes

5b. GRANT NUMBER

\section{AUTHOR(S)}

Hwai-Ping Cheng, Stephen M. England, Clarissa M. Murray

\section{5c. PROGRAM ELEMENT NUMBER}

D31398

5d. PROJECT NUMBER

405372

5e. TASK NUMBER

A1250

5f. WORK UNIT NUMBER

17KGB0

7. PERFORMING ORGANIZATION NAME(S) AND ADDRESS(ES)

Coastal and Hydraulics Laboratory

3909 Halls Ferry Road, Vicksburg, MS 39180-6199;

U.S. Army Corps of Engineers, Philadelphia District (NAP), The Wanamaker Building,

100 Penn Square East, Philadelphia, PA 19107-3390

9. SPONSORING/MONITORING AGENCY NAME(S) AND ADDRESS(ES)

Flood and Coastal Storm Damage Reduction Program

Headquarters, U.S. Army Corps of Engineers

441 G Street NW, Washington, DC 20314-1000
8. PERFORMING ORGANIZATION REPORT NUMBER

ERDC/CHL TR-16-6

\section{SPONSOR/MONITOR'S ACRONYM(S)} HQUSACE-FCSDR

11. SPONSOR/MONITOR'S REPORT NUMBER(S)

\section{DISTRIBUTION/AVAILABILITY STATEMENT}

Approved for public release; distribution is unlimited.

\section{SUPPLEMENTARY NOTES}

\section{ABSTRACT}

The purpose of this Technical Report (TR) is to evaluate the benefits of three-dimensional (3D) modeling of common seepage and piping issues along levees and dikes over traditional two-dimensional (2D) models. To facilitate the evaluation, one 3D model, two 2D crosssectional models, and one 2D plan-view model were developed in this study to simulate a simplified "real-world" situation. This simplified model includes the main channel of a large river, a smaller tributary feeding this river from the north, and levees between the tributary and the river to protect low-lying inland area of concern from flooding. A set of extreme hydrologic conditions was applied to the models, and results from steady-state simulations were compared. Four scenarios, including Existing Condition, Cutoff Wall Only, Relief Wells Only, and Cutoff Wall and Relief Wells, were considered for model comparison. The 2D model results were compared to 3D model results to determine whether they may be sufficient for specified purposes. The results of this analysis indicate several strengths and weakness of both the $2 \mathrm{D}$ and $3 \mathrm{D}$ modeling approaches. The $2 \mathrm{D}$ models are easier to construct and require much less computational time for each simulation. Because a 2D model is assumed to be cut parallel to the flow path, however, complex geologic and topographic features in the real world are likely to result in complex 3D flow fields, which makes it difficult or impossible to define an appropriate 2D cross-sectional model accurately. Moreover, the changes of flow field under project conditions may further limit the usage of 2D models. While a 2D model may be acceptable for a screening level analysis, a 3D model may be deemed informative for a design level analysis.

\section{SUBJECT TERMS}

Computer simulation, Embankments, Groundwater--Mathematical models, Groundwater flow--Computer simulation, Relief wells, Seepage, Saline water barriers, Three-dimensional modeling

\section{SECURITY CLASSIFICATION OF:}

\begin{tabular}{|l|l|l|l|} 
a. REPORT & b. ABSTRACT & c. THIS PAGE & ABSTRACT \\
Unclassified & Unclassified & Unclassified & SAR
\end{tabular}

18. NUMBER OF PAGES

39

\section{9a. NAME OF RESPONSIBLE PERSON Hwai-Ping Cheng}

19b. TELEPHONE NUMBER (Include area code) 601-634-3699 